\title{
Association Between What People Learned About COVID-19 Using Web Searches and Their Behavior Toward Public Health Guidelines: Empirical Infodemiology Study
}

Ikpe Justice Akpan ${ }^{1 *}$, BSc, MSc, PhD; Obianuju Genevieve Aguolu², MD, MPH, PhD; Yawo Mamoua Kobara ${ }^{3^{* *}}$, BSc, MSc; Rouzbeh Razavi ${ }^{4 *}$, BSc, MSc, PhD; Asuama A Akpan ${ }^{5 *}$, BSc, MA; Murali Shanker ${ }^{4 *}$, BSc, MSc, PhD

\footnotetext{
${ }^{1}$ Department of Management \& Information Systems, Kent State University, New Philadelphia, OH, United States

${ }^{2}$ Infectious Disease Internal Medicine Department, Yale School of Medicine, Yale University, New Haven, CT, United States

${ }^{3}$ Statistical and Actuarial Sciences, Western University, London, ON, Canada

${ }^{4}$ Department of Management \& Information Systems, Kent State University, Kent, OH, United States

${ }^{5}$ Research and Development, Ibom International Center for Research and Scholarship, Windsor, ON, Canada

*all authors contributed equally
}

\section{Corresponding Author:}

Ikpe Justice Akpan, BSc, MSc, PhD

Department of Management \& Information Systems

Kent State University

330 University Drive Northeast

New Philadelphia, OH, 44663

United States

Phone: 13303393391 ext 7572

Fax: 13303393321

Email: iakpan@kent.edu

\section{Abstract}

Background: The use of the internet and web-based platforms to obtain public health information and manage health-related issues has become widespread in this digital age. The practice is so pervasive that the first reaction to obtaining health information is to "Google it." As SARS-CoV-2 broke out in Wuhan, China, in December 2019 and quickly spread worldwide, people flocked to the internet to learn about the novel coronavirus and the disease, COVID-19. Lagging responses by governments and public health agencies to prioritize the dissemination of information about the coronavirus outbreak through the internet and the World Wide Web and to build trust gave room for others to quickly populate social media, online blogs, news outlets, and websites with misinformation and conspiracy theories about the COVID-19 pandemic, resulting in people's deviant behaviors toward public health safety measures.

Objective: The goals of this study were to determine what people learned about the COVID-19 pandemic through web searches, examine any association between what people learned about COVID-19 and behavior toward public health guidelines, and analyze the impact of misinformation and conspiracy theories about the COVID-19 pandemic on people's behavior toward public health measures.

Methods: This infodemiology study used Google Trends' worldwide search index, covering the first 6 months after the SARS-CoV-2 outbreak (January 1 to June 30, 2020) when the public scrambled for information about the pandemic. Data analysis employed statistical trends, correlation and regression, principal component analysis (PCA), and predictive models.

Results: The PCA identified two latent variables comprising past coronavirus epidemics (pastCoVepidemics: keywords that address previous epidemics) and the ongoing COVID-19 pandemic (presCoVpandemic: keywords that explain the ongoing pandemic). Both principal components were used significantly to learn about SARS-CoV-2 and COVID-19 and explained 88.78\% of the variability. Three principal components fuelled misinformation about COVID-19: misinformation (keywords "biological weapon," "virus hoax," "common cold," "COVID-19 hoax," and "China virus"), conspiracy theory 1 (ConspTheory1; keyword "5G” or "@5G”), and conspiracy theory 2 (ConspTheory2; keyword "ingest bleach"). These principal components explained $84.85 \%$ of the variability. The principal components represent two measurements of public health safety guidelines-public health measures 1 (PubHealthMes1; keywords "social distancing," "wash hands," "isolation," and "quarantine") and public health 
measures 2 (PubHealthMes2; keyword "wear mask")—which explained 84.7\% of the variability. Based on the PCA results and the log-linear and predictive models, ConspTheory1 (keyword “@5G”) was identified as a predictor of people's behavior toward public health measures (PubHealthMes2). Although correlations of misinformation (keywords "COVID-19," "hoax," "virus hoax," "common cold," and more) and ConspTheory2 (keyword "ingest bleach") with PubHealthMes1 (keywords "social distancing," "hand wash," "isolation," and more) were $r=0.83$ and $r=-0.11$, respectively, neither was statistically significant ( $P=.27$ and $P=.13$, respectively).

Conclusions: Several studies focused on the impacts of social media and related platforms on the spreading of misinformation and conspiracy theories. This study provides the first empirical evidence to the mainly anecdotal discourse on the use of web searches to learn about SARS-CoV-2 and COVID-19.

(J Med Internet Res 2021;23(9):e28975) doi: 10.2196/28975

\section{KEYWORDS}

internet; novel coronavirus; SARS-CoV-2; COVID-19; infodemiology; misinformation; conspiracy theories; public health

\section{Introduction}

\section{Overview}

A novel coronavirus initially named 2019-nCoV emerged in Wuhan, China, and was formally reported to the World Health Organization (WHO) on December 31, 2019 [1-3]. Further scientific evidence soon unveiled the semblance of the 2019-nCoV's genome sequence to a previous epidemic, the severe acute respiratory syndrome (SARS), a disease epidemic caused by SARS-CoV, which broke out in Foshan, China, in 2002 [4,5]. Some initial studies also identified similar features that were related to the Middle East respiratory syndrome (MERS) epidemic caused by MERS-CoV as the causative agent [6].

The outbreak was originally named 2019-nCoV on January 13 , 2020, the same day that the first imported case outside China occurred in the Philippines and other countries [7]. The spread of 2019-nCoV continued across many countries, causing the WHO to declare the outbreak a pandemic [6]. The 2019-nCoV was later renamed SARS-CoV-2 and identified as the causative agent of COVID-19 in February 2020 [8,9]. The highly contagious COVID-19 spread rapidly globally and caught the world unprepared. With no adequately planned health communication strategies, panic ensued, while confirmed cases of infections and deaths from COVID-19 increased rapidly worldwide [3]. The public rushed to internet platforms to learn about the outbreak through Google searches, online news outlets, and social media platforms [10-15].

In March 2020, the WHO launched a free online introductory training course in different languages, including English, French, Spanish, and Chinese, to make the public aware of the contagious COVID-19 [6]. However, it is unclear how many people knew about or used the free training lessons about COVID-19 that the WHO had made available via its website [6]. Instead, several studies suggest that the public flocked to the internet to learn about SARS-CoV-2 and COVID-19 through web searches, online news outlets, and social media [16,17]. Analyzing how people search and navigate the World Wide Web and other internet platforms for health-related information can provide valuable insights into the health-related behavior of populations [18-20]. The public's preference for online health information closely matches the field of infodemiology, a term that is a portmanteau of information and epidemiology. According to Eysenbach [18], the term is defined as the science of distribution and determinants of information in an electronic medium — specifically the internet—or in a population, with the aim to inform public health and public policy. Considering the global spread of COVID-19, using the internet to learn or gain information about the pandemic in this digital age is not surprising, as internet use has become pervasive worldwide $[21,22]$. Several studies have examined social media's influence on what people learned and the appropriate behaviors toward misinformation and conspiracy theories [14,15]. Similarly, Sulyok et al [12] examined the impact of web searches on the confirmed cases of COVID-19 in Europe, while Neely et al [23] investigated information-seeking behaviors on social media regarding the pandemic.

Miller [14,15] identified political leaders' failure in sensitizing the public as a motivating factor that pushed people to the internet as an alternative information source to learn about the COVID-19 pandemic. Misinformation had started flooding the web right from the initial stage of the emergence of the novel coronavirus, mainly from user-created content on social media [24]. Thus, as people turned to the web to search for information, there was limited nontechnical information for the nonexpert public about the coronavirus. Rather, people either got exposed to learning incorrect information about SARS-CoV-2 and COVID-19 or embraced fake news, misinformation, and conspiracy theories, with grave consequences [16]. Some of the unfounded misinformation included misconstruing COVID-19 as a "common cold" or as a hoax, which made people have a false sense of immunity, while others ignored any public health safety measures [11]. Similarly, the conspiracy theories propagated online included that COVID-19 was a bioweapon, that China intentionally released the virus to reduce the world population, and that $5 \mathrm{G}$ technology contributed to the fast spread of the pandemic. These beliefs initially led to the hoarding of essential goods as well as racial attacks against Chinese and other Asian people [14,15,25,26].

Other studies examined the role of social media and internet news outlets in generating misinformation, disinformation, fake news, and conspiracy theories about COVID-19 [25,27-29]. These studies tend to leave out the aspect of web searching, such as the use of Google searches, which constitutes a major 
channel through which the public obtain health-related information [30,31].

\section{Research Objectives}

This paper undertakes the first empirical investigation using a web search to learn about SARS-CoV-2 and COVID-19 and people's attitudes toward public health guidelines as expressed in the following research objectives:

1. Determine what people learned about the COVID-19 pandemic through web searching.

2. Examine any association between what people learned about COVID-19 and behavior toward public health guidelines.

3. Analyze the impact of misinformation and conspiracy theories about the COVID-19 pandemic on people's behavior toward public health measures.

These objectives are developed into research hypotheses in the sections that follow.

\section{Theoretical Background}

\section{The Connectivism Learning Theory}

This section examines the connectivism learning theory, which explains the use of digital platforms to enable learning $[32,33]$. This study employs this approach to explore how people learned about SARS-CoV-2 and COVID-19 through web searching and the potential behavioral implications toward public health guidelines, which scientists and medical experts recommend as ways to check the spread of COVID-19. For example, the study investigates if learning through web searching helped people acquire accurate knowledge or misinformation and conspiracy theories about the COVID-19 pandemic and its implications. Also, recent studies show that many people have yet to understand the science and the concept of SARS-CoV-2 and the disease, COVID-19, which increases the danger of embracing misinformation [14,28]. Several web platforms, including social media, online news, and other internet channels, contribute significantly to misinformation and conspiracy theories [14,34].

According to Dunaway [33], the connectivism theory developed by George Siemens analyzes the use of digital devices, computer networks, and electronic platforms to learn. The view is considered a pedagogical strategy for the digital age, emphasizing knowledge sharing across an interconnected web and internet network [32,33]. The approach focuses on knowledge acquisition using information technology platforms and learning from multiple sources, developing skills, and disseminating information [32]. The platforms incorporate information on social media, internet websites or blogs, and search engines that users can employ to learn and exchange knowledge, skills, and expertise [28,33].

\section{Implications of the Connectivism Learning Theory}

One of the implications of the connectivism learning theory is that learning can occur outside the traditional classroom by using networked systems that enhance connections, interactions, and collaborations among learners [29]. However, some learning theory experts criticize the connectivism theory for not offering any improvement to the actual learning method other than using
Web 2.0 and related platforms [32,33]. Hence, it cannot be deemed a substantive learning theory. Instead, it provides a bridge to other pedagogical methods: behaviorism, cognitivism, and constructivism. The core of the Siemens and Downes connectivism idea aims to move away from the traditional classroom learning techniques to a new theory of learning that embraces technology as the learning tool, which can inspire the new generation of learners and educators $[32,33]$. Thus, the theory draws its strength from web-based activities [29].

The key benefit of the method is its intuitiveness and its ability to captivate learners due to the ubiquitous use of the internet in today's world. The following principles contribute to the popularity of connectivism as a learning theory [33]:

1. Learning and knowledge rest in diversity of opinions, as experienced today.

2. Learning is a process of connecting specialized nodes or information sources.

3. Learning may reside in nonhuman appliances.

4. The capacity to know more is more critical than what is currently known.

5. Nurturing and maintaining connections help to facilitate continual learning.

6. Ability to see connections between fields, ideas, and concepts is a core skill.

7. Currency (accurate, up-to-date knowledge) is the intent of all connectivism learning activities.

8. Decision making is itself a learning process. Choosing what to learn and the meaning of incoming information is seen through a shifting reality.

The connectivism learning theory, as explained above, closely mirrors the use of Google Trends and other internet platforms to learn about the outbreak of SARS-CoV-2 and COVID-19, especially where the masses did not get adequate, timely information about the coronavirus from the public agencies [35,36].

The connectivism learning theory is well suited to personal study and self-regulated learning [37,38]; in this case, how individual members of the public learned about SARS-CoV-2 and COVID-19 using web searches in the first 6 months of the COVID-19 pandemic.

\section{An Overview of the SARS-CoV-2 Outbreak and the COVID-19 Pandemic}

\section{The Global Impacts of the SARS-CoV-2 Outbreak}

The COVID-19 pandemic has caused severe problems ranging from health crises to psychological, social, business, and economic consequences all over the world [16,18,39]. Meanwhile, there is currently no specific cure for COVID-19. However, there has been significant progress in technological advances leading to substantial breakthroughs in vaccine discovery and development through the pioneering efforts of Pfizer, Moderna, and other companies from the United Kingdom, India, China, and other countries [40]. Administering the COVID-19 vaccines is ongoing worldwide, while several other vaccine discoveries and developments are in progress [41]. In the meantime, ongoing prevention, monitoring, and 
public health awareness are essential to mitigate the public health and economic burdens. The most important prevention strategy is to understand the disease and how it spreads.

\section{Transmission}

Coronavirus transmission primarily occurs through respiratory droplets released from infected persons during coughing, sneezing, or speech. One can also become infected with the virus via contact with contaminated surfaces. The virus can remain infectious in the air for 3 hours and on inanimate surfaces for up to 9 days or longer. This has implications for nosocomial spread and superspreading events [42]. The virus has also been isolated from blood, urine, and stool specimens. It is important to note that asymptomatic infected people may not be aware that they are infected because they do not have the symptoms or may not recognize the symptoms. Infected individuals can be contagious for up to 4 weeks and can unknowingly be spreading the infection during this time [42].

\section{Clinical Presentation and Diagnosis}

Symptoms usually appear 2 to 14 days after exposure. Most confirmed cases of SARS-CoV-2 infection are asymptomatic, and they recover without treatment. Common symptoms include fever, cough, shortness of breath, chills, myalgia, headache, sore throat, anosmia, and dysgeusia. Severe cases present with dyspnea, tachypnea, hypoxia (blood oxygen saturation $\leq 93 \%$ ), a ratio of the arterial partial pressure of oxygen to the fraction of inspired oxygen of less than $300 \mathrm{~mm} \mathrm{Hg}$, and lung infiltration [43]. Some patients present with gastrointestinal symptoms, such as vomiting, diarrhea, and abdominal pain, as well as cardiovascular features, such as arrhythmia, shock, and acute cardiac injury [44]. There have been reports of asymptomatic carriers presenting with symptoms such as loss of smell and taste. In children, the majority present with mild (ie, fever, cough, fatigue, and congestion) or moderate (ie, pneumonia) symptoms [44]. Some may be asymptomatic. Children under 5 years old may present with respiratory organ failure.

Chest computed tomography scans shows a distinct appearance of ground-glass lung opacity, often bilateral, in patients who develop pneumonia [43]. Other radiographic features, such as "crazy-paving sign, multifocal organizing pneumonia, and architectural distortion in a peripheral distribution," may appear with disease progression. Diagnostic testing is performed from respiratory (ie, nose, throat, and saliva) and serum samples, using a real-time reverse transcription-polymerase chain reaction panel or antibody test. Viral RNA has also been detected in stool and blood [5].

\section{Complications}

Some hospitalized patients develop thromboembolism, especially deep venous thrombosis, and pulmonary embolism. Other complications include microvascular thrombosis of the toes, clotting of catheters, myocardial injury with ST-segment elevation, and large vessel strokes. This complication may be associated with the release of high levels of inflammatory cytokines and activation of the coagulation pathway caused by hypoxia and systemic inflammation secondary to COVID-19 [45].

\section{Prevention and Control}

People must be well-informed. Infected persons must practice respiratory etiquette to avoid infecting others, including covering coughs and sneezes with a tissue and discarding it properly, coughing into the inside of the elbow, and covering the nose and mouth properly with a surgical face mask. Best practices include proper handwashing with soap and water for at least 20 seconds or at least $60 \%$ alcohol-based hand rub. Touched surfaces must be cleaned frequently with disinfectants. People must avoid touching the eyes, nose, and mouth with unwashed hands and they must avoid close contact with people who are ill [46]. The US Centers for Disease Control and Prevention (CDC) recommends that infected and exposed individuals must isolate or quarantine themselves, respectively, for at least 14 days. The CDC also recommends social distancing, including avoiding mass gatherings or large community events, shaking hands, or giving "high fives" [41]. In health care settings, standard contact and airborne precautions, as well as eye protection, should be used to mitigate the spread of SARS-CoV-2 [46]. There is no specific cure for COVID-19. Management is mainly supportive care and treatment of secondary infections. Severely ill patients may need advanced organ support.

\section{Methods}

\section{Google Trends and Search Keywords About SARS-CoV-2 and COVID-19}

This study used an infodemiology approach to evaluate the use of web searching to learn about SARS-CoV-2 and COVID-19. As an area of scientific research, infodemiology is a method or technique designed to measure and track health information "demand" automatically (eg, by analyzing search queries) as well as "supply" on the internet $[18,20,47]$. The goal is to inform public health policy and practice. This study uses data from Google Trends, a freely available online resource that provides information on what was and is trending based on actual users' Google queries [11,48,49].

Google Trends offers various search options, such as "Trending Searches" (ie, trending queries for daily search trends and real-time searches in a selected region) or "Year in Search" (ie, what was trending in a specific area in a particular year). Another option is to "Explore," which allows an investigation of an area of interest based on keywords over the selected periods and regions. This study uses the "Explore" option, which allowed data to be retrieved directly from the Google Trends "Explore" page in comma-separated values format. It is also important to note that Google Trends data points are normalized to have a maximum value of 100 and a minimum value of 0 . We normalized the data set by dividing each data point by total searches of the geography and the time range it represents to compare relative popularity. Note that the value 0 does not necessarily indicate no searches but represents a significantly low search volume that does not warrant inclusion in the results [47].

In this study, we captured the worldwide Google Trends data covering the initial months of the SARS-CoV-2 outbreak from 
January 1 to June 30, 2020 (ie, 182 daily data points for each search term). Regarding the search terms, this paper employed 25 keywords and phrases used by the public to learn about the COVID-19 pandemic through web searches. We identified the search keywords (Table 1) through a literature survey of published documents indexed on the Web of Science. Six search terms were related directly to the ongoing pandemic: "nCoV," "2019-nCoV," "SARS-CoV-2," "COVID-19," "pandemic," and "coronavirus." Another six keywords addressed previous viral or coronavirus epidemics: "SARS-CoV," "SARS," "MERS-CoV," "MERS," "virus," and "influenza." The third category of search terms represented public health safety measures that experts recommended as guidelines to limit the spread of COVID-19: "social distancing," "wear a facial mask," and "wash hands." The final category of keywords represented misinformation and conspiracy theories, such as "China virus," "common cold," and "bioweapon" (Table 1 $[2,3,6,7,9,11,14,15,25-27,42,46,50-60])$.

Table 1. Web search terms used to learn about SARS-CoV-2 and the COVID-19 pandemic, misinformation and conspiracy theories, and public health safety guidelines, based on a literature review.

\begin{tabular}{|c|c|}
\hline Category & Search terms \\
\hline COVID-19 and related epidemics & 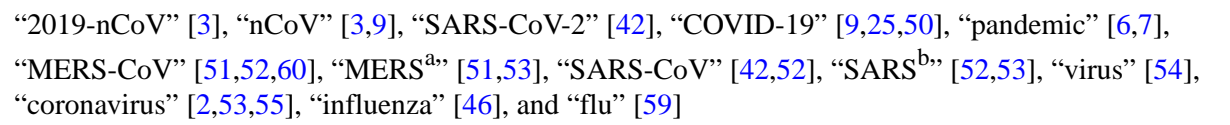 \\
\hline Misinformation and conspiracy theories & $\begin{array}{l}\text { "virus hoax" }[14,15] \text {, "injecting or ingesting bleach" [56], "5G" or "@ 5G" technology enhancing the } \\
\text { spread of the virus [25,27], "COVID-19 hoax" [14,15,26], "common cold" ("commoncold2020") [11], } \\
\text { "China virus" [50], and "bioweapons" created by China [14,25,60] }\end{array}$ \\
\hline Public health measures & $\begin{array}{l}\text { "social distancing" [57], "wash hands" or "hands wash" [57], "wear a facial mask" [58], "isolation" } \\
\text { [57], and "quarantine" [57] }\end{array}$ \\
\hline
\end{tabular}

${ }^{\text {a} M E R S: ~ M i d d l e ~ E a s t ~ r e s p i r a t o r y ~ s y n d r o m e . ~}$

${ }^{\mathrm{b}}$ SARS: severe acute respiratory syndrome.

\section{Research Hypotheses}

\section{Hypothesis 1}

For the purpose of determining what people learned about the COVID-19 pandemic through web searching, we defined the null and alternative hypotheses as follows:

- Hypothesis $1_{0}$ : People did not learn about COVID-19 through web searching using the identified keywords.

- Hypothesis $1_{1}$ : People learned about COVID-19 through web searching using the identified keywords.

\section{Hypothesis 2}

Based on the literature, using a web search to learn about a subject of interest can influence the learner's decision making and actions [61]. On this premise, this study examined any association between what people learned about COVID-19 and people's behavior toward the public health guidelines. We developed two separate hypotheses (Hypotheses 2 and 3). The first aspect related to web searching to learn about COVID-19 (ie, concept, science, and structure of SARS-CoV-2 and COVID-19), while the second aspect evaluated learning about misinformation and conspiracy theories as well as the behavioral response to the public health measures. The null and alternative hypotheses regarding the first aspect are as follows:

- Hypothesis $2_{0}$ : There is no association between what people learned about COVID-19 through web searching and behavior toward public health measures.

- Hypothesis $2_{1}$ : There is an association between what people learned about COVID-19 through web searching and behavior toward public health measures.

\section{Hypothesis 3}

There is a widely held assertion that misinformation and conspiracy theories about the COVID-19 pandemic have had a significant impact on people's behavior toward public health measures. We defined the null and alternative hypotheses for learning about misinformation as follows:

- Hypothesis $3 \mathrm{~A}_{0}$ : There is no association between misinformation learned about COVID-19 and people's behavior toward public health measures.

- Hypothesis $3 \mathrm{~A}_{1}$ : There is an association between misinformation learned about COVID-19 and people's behavior toward public health measures.

Similarly, we defined the null and alternative hypotheses for learning about conspiracy theories as follows:

- Hypothesis $3 \mathrm{~B}_{0}$ : There is no association between conspiracy theories learned about COVID-19 and people's behavior toward public health measures.

- Hypothesis $3 \mathrm{~B}_{0}$ : There is an association between conspiracy theories learned about COVID-19 and people's behavior toward public health measures.

\section{Data Analysis}

Data analysis employed statistical trends and graphical visualization, correlation and regression, principal component analysis (PCA), and predictive models [12,56,62-64]. The statistical trends and analyses involved evaluating relationships among the listed variables using the statistical trends, including graphical display, correlation, and PCA, which helped determine the predictiveness of the learning attributes and learners' actions toward public health guidelines. We used the JMP 15 package from SAS software (SAS Institute Inc) [65] for statistical 
analysis and Microsoft Excel 2019 to create the charts and graphs. We also used SPSS software (version 27; IBM Corp) to compute the correlation matrix and the PCA as well as statistical packages in $\mathrm{R}$ (version 4.0.5; The R Foundation) for the linear modeling. The evaluation helped establish the correlation between the study attributes.

\section{Results}

\section{Overview}

The data analyzed in this study came from the Google Trends worldwide index covering the period from the initial outbreak of COVID-19 on January 1, 2020, up to June 30, 2020, when the pandemic became widely known [2]. The outbreak had been reported to the WHO's office in China on December 31, 2019 [6]. The reason for focusing on the first 6 months of the pandemic was to capture what people learned during the early days of the outbreak as well as the possible impacts of what people learned through web searching on individuals' attitudes toward public health safety measures.

To better understand the characteristics of Google Trends data, we have presented the summary statistics of the daily search index for each of the 25 keywords or search terms and phrases (Table S1 in Multimedia Appendix 1). The average normalized scores for the terms varied from 2.65 ("ingesting bleach") to 39.75 ("SARS-CoV-2"), as shown in Table S1 in Multimedia Appendix 1.

\section{Temporal Trends: Using Web Searches to Learn About SARS-CoV-2}

The keywords employed to conduct web searches indicate what people learned about the COVID-19 pandemic [66]. As presented in Table 1, some of the search keywords addressed the novel coronavirus directly, while others examined misinformation and conspiracy theories.

Figure 1 presents the first category of web search terms that people used to learn about the COVID-19 pandemic. In the early period, most people used keywords and phrases that explain previous coronavirus epidemics, including "influenza," "MERS," "MERS-CoV," "SARS," and "virus." Although scientists ruled out the past epidemics, the WHO officials highlighted those terms as examples of past coronavirus outbreaks during press briefings [6]. The use of those keywords in the web searches nosedived after the WHO formally named the novel coronavirus and the disease (ie, "nCoV," "2019-nCoV," "SARS-CoV-2," and "COVID-19"). The coefficients of determination $\left(R^{2}\right)$ of the keywords are 0.37 for "SARS-CoV-2," 0.36 for "COVID-19," 0.27 for "influenza," 0.24 for "2019-nCoV," 0.18 for "nCoV," 0.12 for "SARS," and 0.11 for "SARS-CoV," indicating the proportion of the variation in the search index over the period for the listed keywords. Similarly, the search terms "MERS," "MERS-CoV," "pandemic," "virus," "coronavirus," "nCoV," and "2019-nCoV" had $R^{2}$ values of less than 0.1 .

Figure 1. The keywords used by people to learn about SARS-CoV-2 and COVID-19 through web searches. MERS: Middle East respiratory syndrome; SARS: severe acute respiratory syndrome.

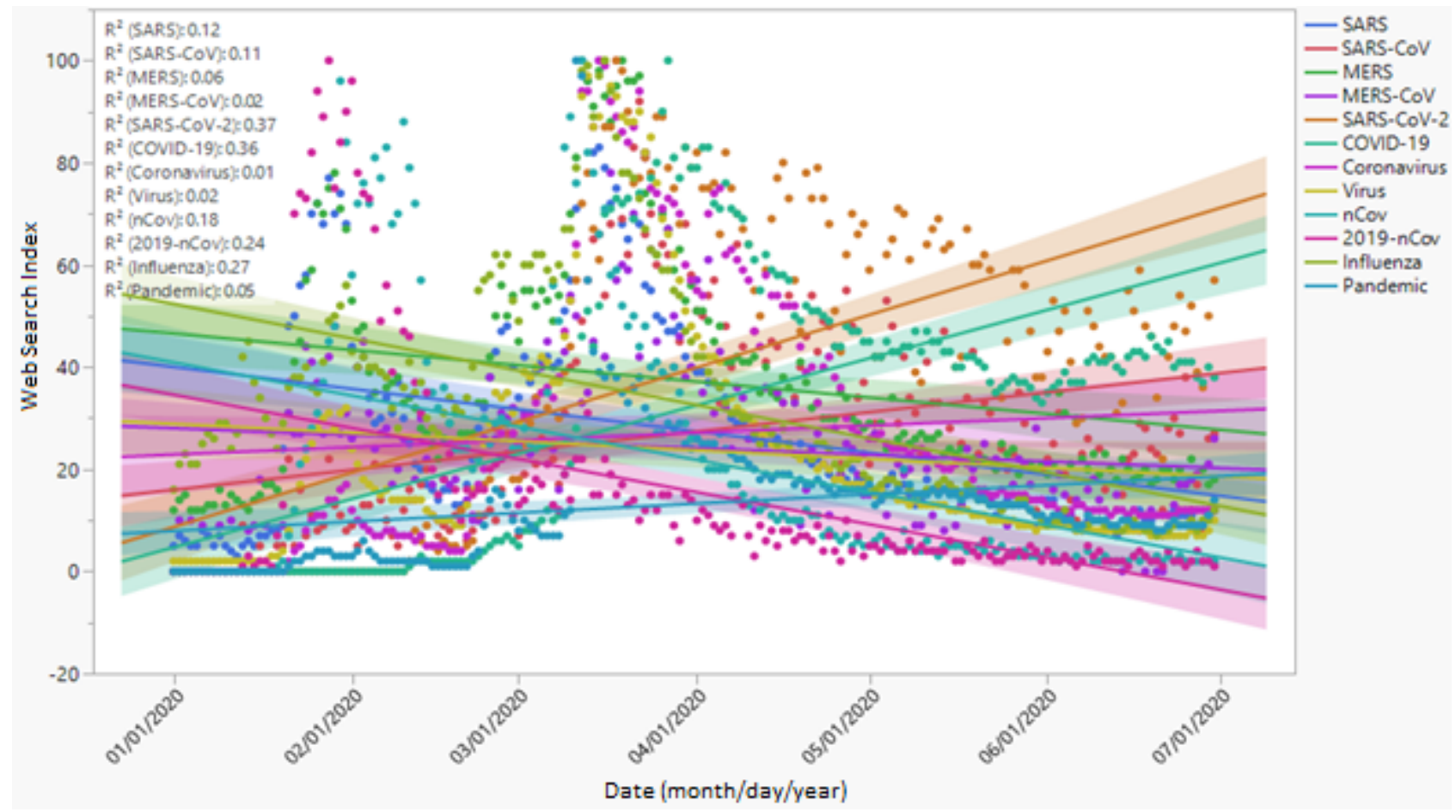

The second category of keywords involved misinformation and conspiracy theories (Figure 2). The variation in the use of the terms was measured using coefficients of determination $\left(R^{2}\right)$, which were 0.15 for "China virus," 0.10 for "common cold," and 0.09 for "5G” or “@ $5 \mathrm{G}$.” Most searches in the initial months of the outbreak used the keywords "common cold" ("cold2020"), "biological weapon," and "China virus," thus encouraging the misconception about SARS-CoV-2 as a "common cold," a "biological weapon," or a "China virus" [50]. Some studies explain that the purpose of releasing the coronavirus was to reduce the world population $[14,25]$. However, web searches 
using these terms fell continuously over time to a near-zero surfaced and increased significantly (Figure 2). search index, while new words ("5G" and "COVID-19 hoax")

Figure 2. Worldwide search index showing the learning terms that represent misinformation and conspiracy theories about COVID-19.

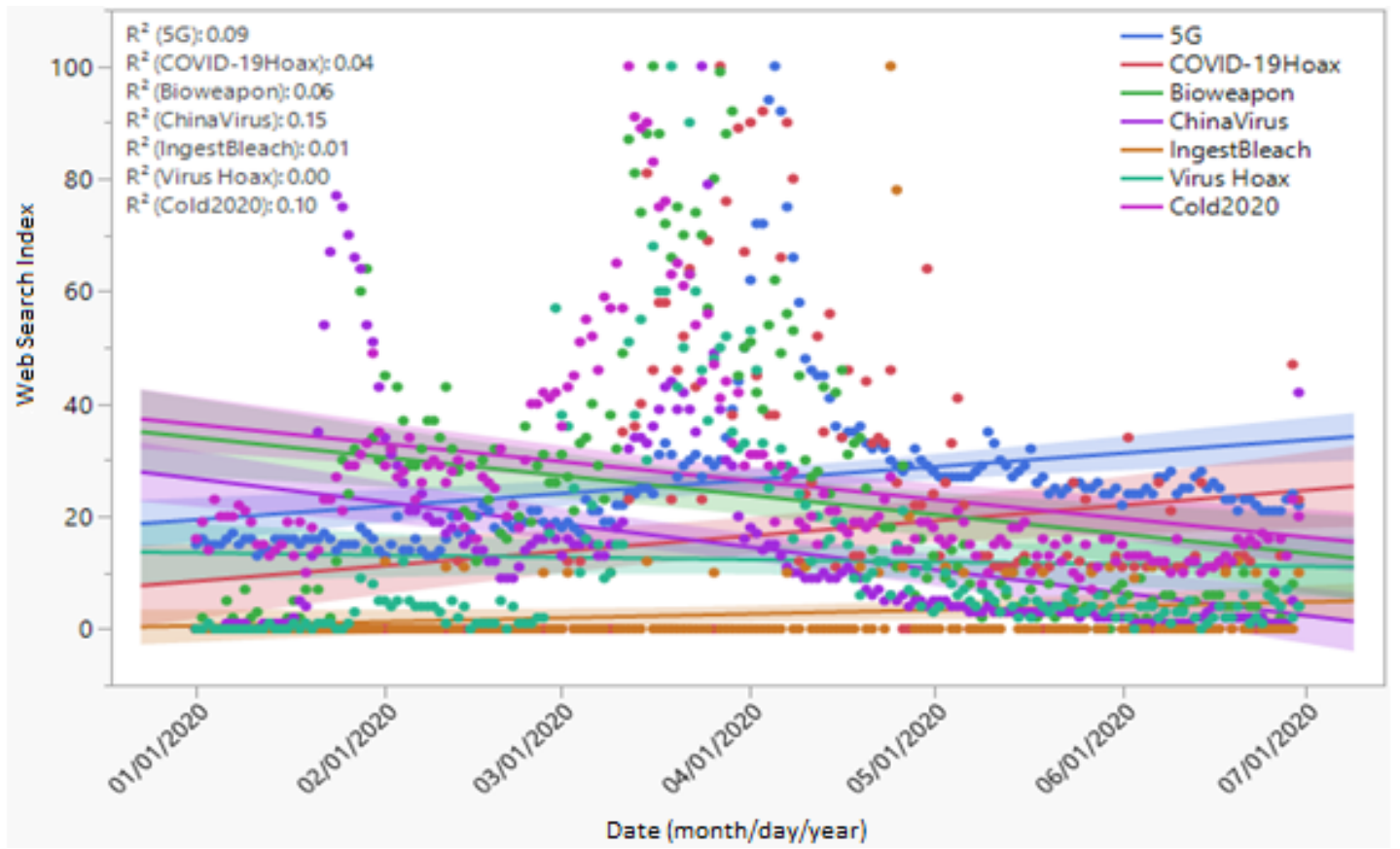

The third segment of the trend analysis involved web searches to learn about public health measures (Figure 3). The results show that there was little or no interest in learning about wearing a facial mask ("wear mask") and maintaining social distancing ("social distancing") at the start of the pandemic. But the trends changed quite quickly, recording a dramatic increase from a search index of 0 at the beginning of the outbreak to achieving a maximum search index of 100 in March and April 2020, as the pandemic spread worldwide. The coefficients of determination were as follows: "wear mask" $\left(R^{2}=0.56\right)$, "social distancing" $\left(R^{2}=0.13\right)$, and "quarantine" $\left(R^{2}=0.09\right)$. The increases, especially regarding "wear mask" and "social distancing," were sustained for a long time.

Figure 3. Trend analysis showing the web search index for learning about public health safety measures.

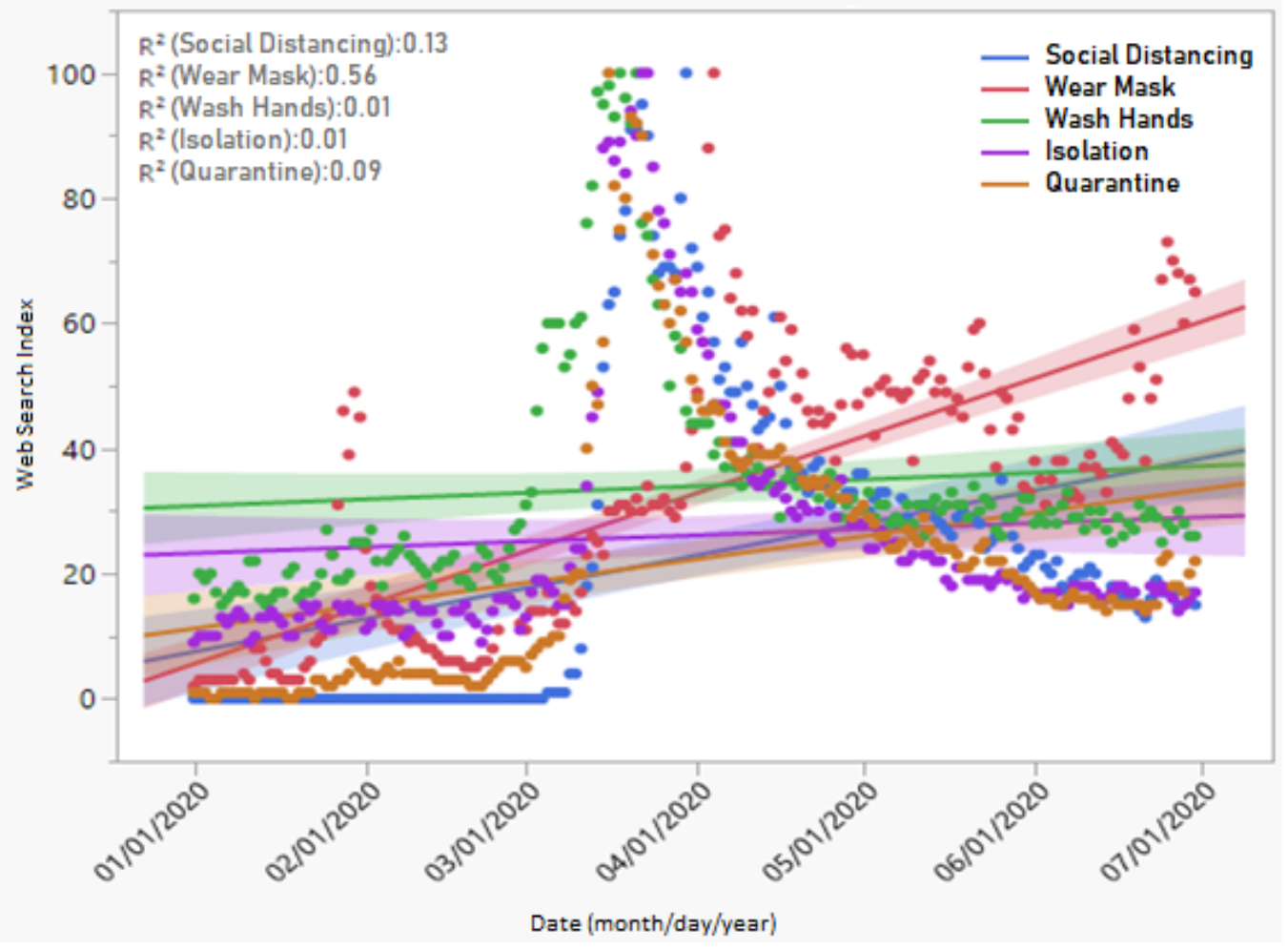




\section{What Did People Learn About COVID-19 Through Web Searches?}

The keywords identified above approximate what people learned about SARS-CoV-2 and COVID-19 through web searches. However, some of the search keywords existed before the ongoing pandemic, while some terms referred to previous coronavirus epidemics (eg, "SARS," "SARS-CoV," "MERS," "MERS-CoV," “influenza," "virus," "pandemic," and "coronavirus"). It is plausible to argue that the search index for the pre-existing keywords listed represent purposes other than learning about COVID-19. Based on this assumption, we conducted a dependent two-sample $t$ test to examine the difference in the mean search index of the pre-existing keywords in the previous years before the COVID-19 outbreak and during the ongoing pandemic. Figure 4 compares the mean search index before and after the outbreak for each keyword.

Figure 4. The average search index for pre-existing keywords before and during the COVID-19 pandemic. MERS: Middle East respiratory syndrome; SARS: severe acute respiratory syndrome.

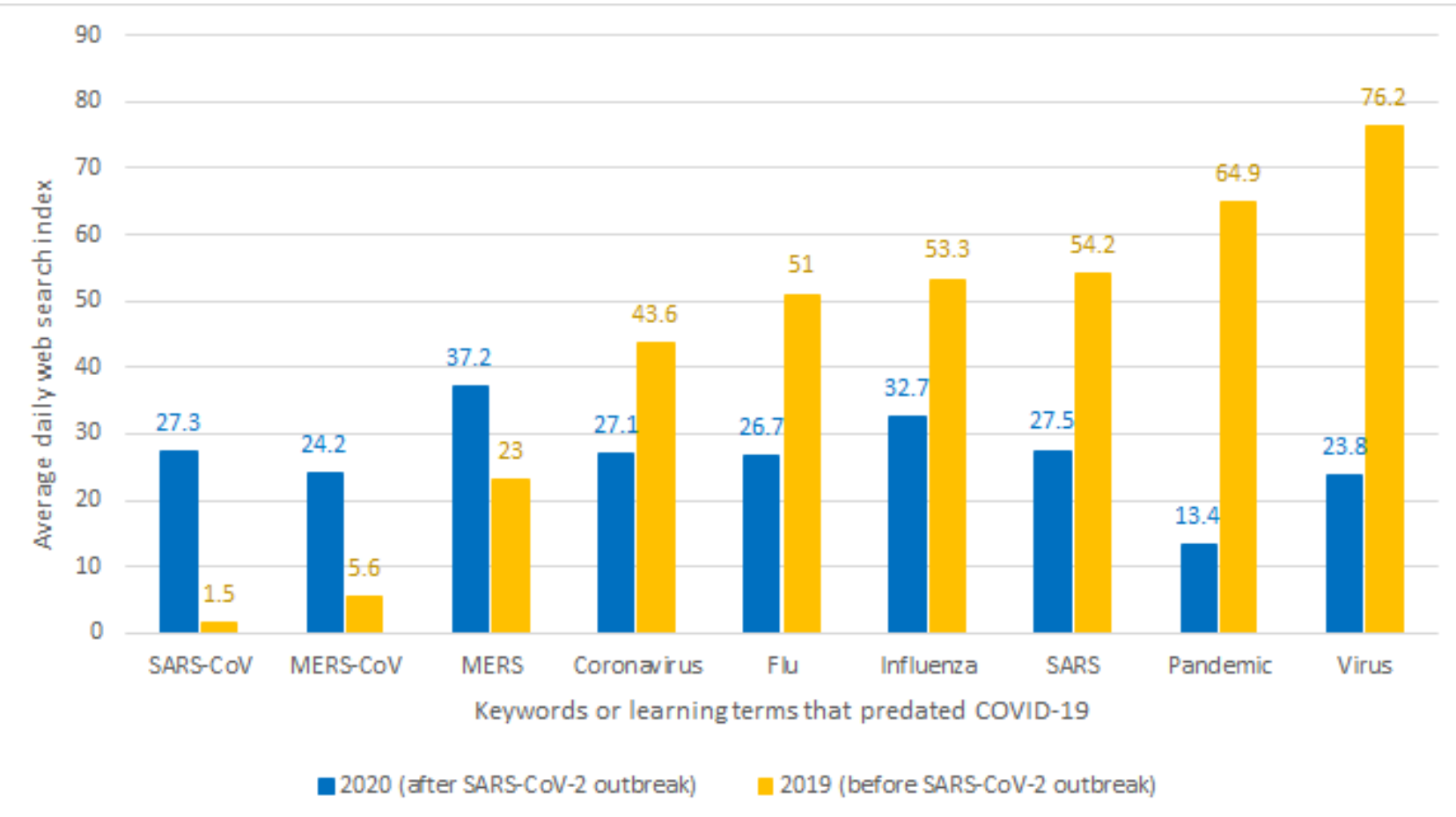

The null hypothesis was that the search indexes of each learning term-“SARS," "SARS-CoV," "MERS," "MERS-CoV," "influenza," "virus," "pandemic," and "coronavirus"-before and after the outbreak of COVID-19 would be equal, and the alternative hypothesis was that they would be unequal. The results, as seen in Figure 4, show that the differences in the mean search indexes before and during the ongoing pandemic were more than $60 \%$ in all cases. Also, the $P$ values were close to zero for all the variables. We rejected the null hypothesis and concluded that the significant differences in the mean search indexes of the variables were due to the ongoing COVID-19 pandemic. Unexpectedly, the mean search index for some pre-existing keywords (eg, "flu," "influenza," "SARS," "pandemic," and "virus") declined during the pandemic.

\section{What Search Terms Contributed to Learning About SARS-CoV-2 and COVID-19?}

PCA was employed to evaluate the underlying latent variable of the search terms that contributed to learning about COVID-19. Based on the scree plot and the elbow rule, we can limit the factors extracted to the first two principal components (Figure 5): the keywords that address previous epidemics (pastCoVepidemics) and the keywords that explain the ongoing pandemic (presCoVpandemic). A scree plot is a graphical representation of the percentage variability explained by each principal component. 
Figure 5. Scree plot of COVID-19 learning terms; two principal components extracted $88.78 \%$ of the total variation.

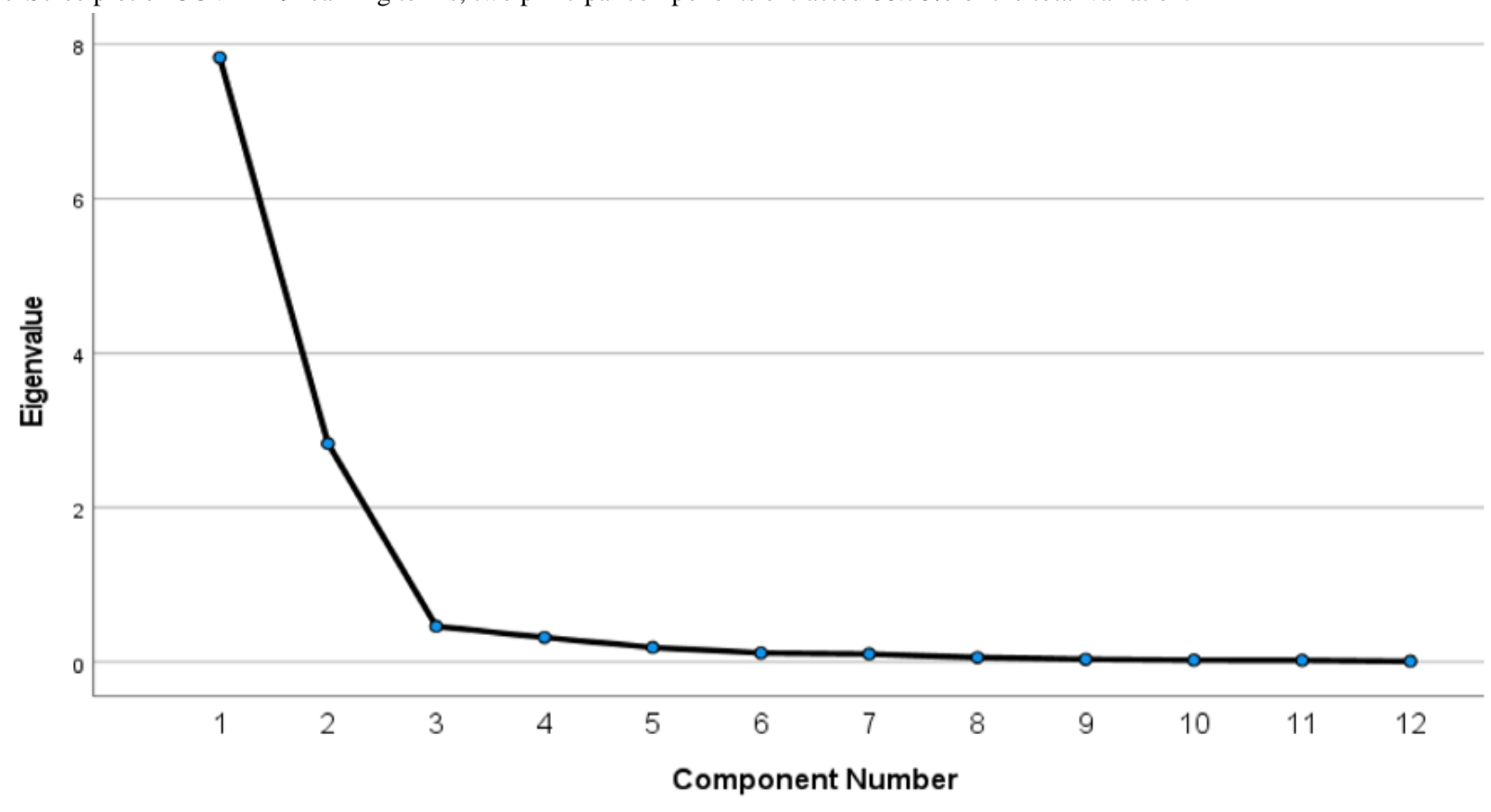

The first two underlying components explained a total of $88.78 \%$ components determining about $65.2 \%$ and $23.58 \%$, respectively, of the variation in learning terms, with the first of the information about COVID-19 from the 12 search (pastCoVepidemics) and second (presCoVpandemic) keywords (Table 2).

Table 2. Total explained variance for search keywords used to learn about COVID-19.

\begin{tabular}{llllllllllllll}
\hline Measure & PC 1 & PC 2 & PC 3 & PC 4 & PC 5 & PC 6 & PC 7 & PC 8 & PC 9 & PC 10 & PC 11 & PC 12 \\
\hline Total initial eigenvalue & 7.82 & 2.83 & 0.46 & 0.32 & 0.19 & 0.12 & 0.11 & 0.06 & 0.04 & 0.03 & 0.02 & 0.01 \\
Variance, \% & 65.20 & 23.58 & 3.86 & 2.65 & 1.57 & 0.98 & 0.88 & 0.49 & 0.29 & 0.21 & 0.19 & 0.09 \\
Cumulative variance, \% & 65.20 & 88.78 & 92.64 & 95.30 & 96.87 & 97.84 & 98.72 & 99.21 & 99.51 & 99.72 & 99.91 & 100 \\
\hline
\end{tabular}

${ }^{\mathrm{a}} \mathrm{PC}$ : principal component.

Linear combinations of the two components (pastCoVepidemics and presCoVpandemic) are as follows:

- $\quad$ PastCoVepidemics $=0.98$ "virus" + 0.934 "coronavirus" + 0.929 "MERS" + 0.923 "flu" + 0.858 "MERS-CoV" + 0.858 "SARS" + 0.791 "SARS-CoV" + 0.799 "pandemic" +0.814 "influenza"
- $\quad$ PresCoVpandemic $=-765$ "nCoV" + 0.784 "COVID-19" + 0.766 "SARS-CoV-2."

Table 3 shows the weights (loadings) of the terms for the two components. Note that we record loadings greater than 0.6 to combine only search keywords that have a high correlation with the component in the linear combinations.

Table 3. Component matrix and weight loadings for search keywords used to learn about COVID-19.

\begin{tabular}{|c|c|c|c|c|c|c|c|c|c|c|c|c|}
\hline \multirow[t]{2}{*}{ Component $^{\mathrm{a}}$} & \multicolumn{12}{|c|}{ Weight loading for each keyword } \\
\hline & $\begin{array}{l}\text { Virus } \\
2020\end{array}$ & $\begin{array}{l}\text { Coronavirus } \\
2020\end{array}$ & $\begin{array}{l}\text { MERS }^{b} \\
2020\end{array}$ & $\begin{array}{l}\text { Flu } \\
2020\end{array}$ & $\begin{array}{l}\text { MERS- } \\
\text { CoV } \\
2020\end{array}$ & $\begin{array}{l}\text { SARS }^{c} \\
2020\end{array}$ & $\begin{array}{l}\text { Influenza } \\
2020\end{array}$ & $\begin{array}{l}\text { Pandemic } \\
2020\end{array}$ & $\begin{array}{l}\text { SARS- } \\
\text { CoV } \\
2020\end{array}$ & $\begin{array}{l}\text { COVID- } \\
19\end{array}$ & $\begin{array}{l}\text { SARS- } \\
\text { CoV-2 }\end{array}$ & 2019-nCoV \\
\hline 1 & 0.98 & 0.934 & 0.929 & 0.923 & 0.858 & 0.858 & 0.814 & 0.799 & 0.791 & 0.562 & 0.601 & 0.45 \\
\hline 2 & -0.059 & 0.278 & -0.305 & -0.278 & -0.121 & -0.443 & -0.477 & 0.315 & 0.505 & 0.784 & 0.766 & -0.765 \\
\hline
\end{tabular}

${ }^{\mathrm{a}}$ Component 1 is pastCoVepidemics (keywords that address previous epidemics) and component 2 is presCoVpandemic (keywords that explain the ongoing pandemic).

bMERS: Middle East respiratory syndrome.

${ }^{\mathrm{c}} \mathrm{SARS}$ : severe acute respiratory syndrome. 


\section{What Terms Fueled Misinformation and Conspiracy Theories About COVID-19?}

We identified eight search keywords from the literature that denote misinformation and conspiracy theories (Table 1). We also performed a PCA to evaluate the search terms that fueled misinformation and conspiracy theories. The results, as seen in Table 4 and Figure 6, identified three principal components and their variabilities based on the elbow rule: principal component $1(48.17 \%)$, principal component $2(22.65 \%)$, and principal component 3 (14.03\%).

Table 4. Total variance explained involving terms that fueled misinformation and conspiracy theories.

\begin{tabular}{llllllll}
\hline Measure & PC $^{\mathrm{a}} 1$ & PC 2 & PC 3 & PC 4 & PC 5 & PC 6 & PC 7 \\
\hline Total initial eigenvalue & 3.372 & 1.586 & 0.982 & 0.496 & 0.257 & 0.176 & 0.132 \\
Variance, \% & 48.171 & 22.652 & 14.026 & 7.085 & 3.669 & 2.509 & 1.888 \\
Cumulative variance, \% & 48.171 & 70.823 & 84.849 & 91.934 & 95.603 & 98.112 & 100 \\
\hline
\end{tabular}

${ }^{\mathrm{a}} \mathrm{PC}$ : principal component.

Figure 6. Scree plot of misinformation and conspiracy theory terms.

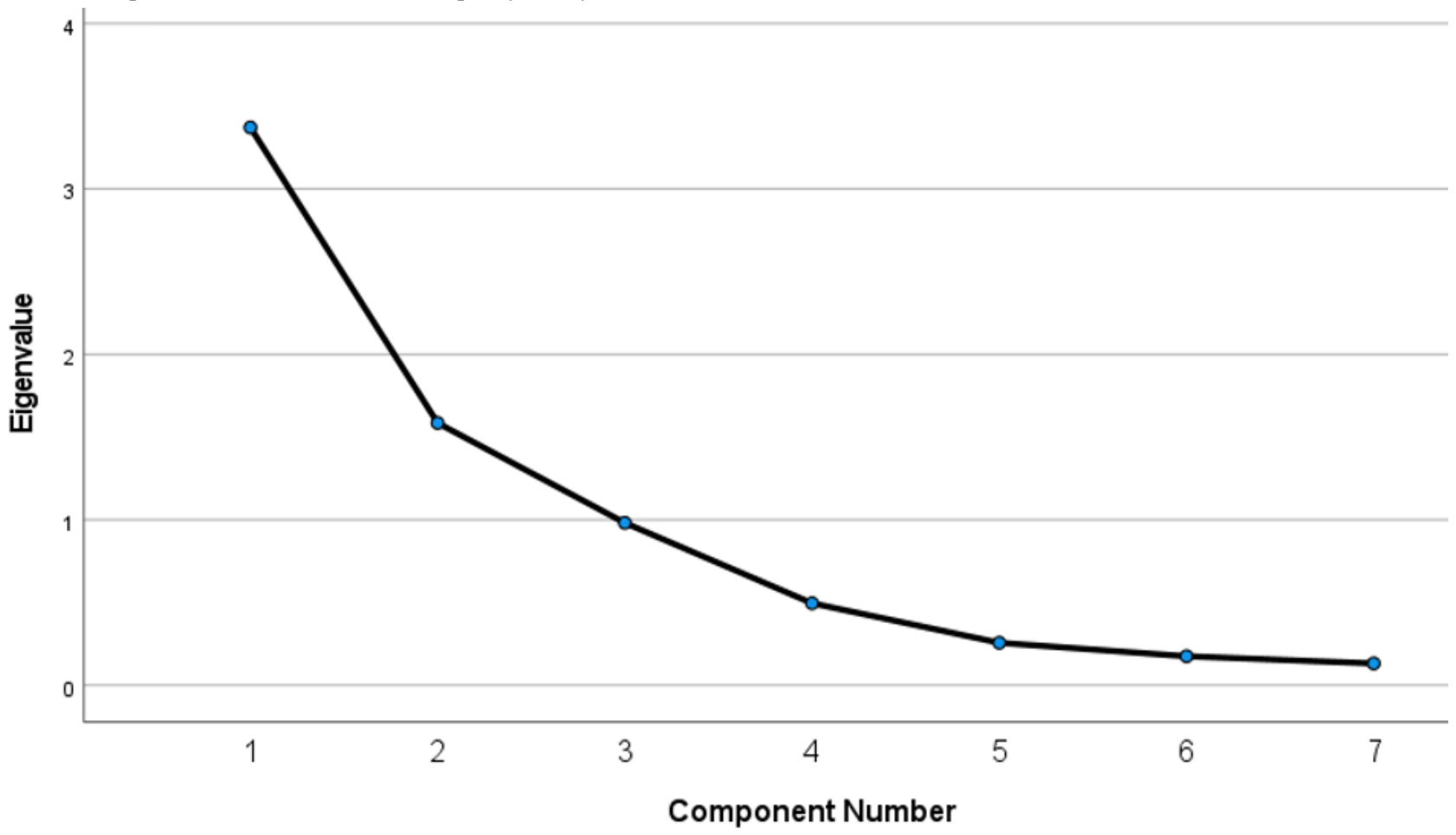

The three components explained $84.85 \%$ of the variation in the search keywords under misinformation and conspiracy theories. The first component represented misinformation. We quantified the daily number of misinformation terms searched using the linear combination as follows:

- Misinformation $=0.789$ "common cold" +0.928 "bioweapon" + 0.908 "virus hoax" + 0.875 "cold 2020" + 0.692 "COVID-19 hoax" + 0.60 "China virus."
The second and third components addressed two conspiracy theories (ConspTheory1 and ConspTheory2), which speculated that $5 \mathrm{G}$ technology contributes to the spreading of COVID-19, that COVID-19 is a "China virus" that was intentionally created and released, and that ingesting or injecting bleach can cure COVID-19 infection or kill the virus. The results present these variables in the separate components (Table 5) as follows:

- ConspTheory1=0.786 “@5G”

- ConspTheory2 = 0.97 "ingest bleach." 
Table 5. Component matrix and weight loading for terms that fueled misinformation and conspiracy theories.

\begin{tabular}{llllllll}
\hline Component $^{\mathrm{a}}$ & \multicolumn{2}{l}{ Weight loading for each keyword } & & & & \\
& Bioweapon 2020 & Virus hoax & Common cold 2020 & COVID-19 hoax & China virus & @5G & Ingest bleach \\
\hline 1 & 0.928 & 0.908 & 0.789 & 0.692 & 0.601 & 0.471 & -0.045 \\
2 & -0.152 & 0.033 & -0.438 & 0.624 & -0.558 & 0.786 & 0.226 \\
3 & 0.03 & 0.005 & 0.093 & -0.044 & 0.059 & -0.145 & 0.973 \\
\hline
\end{tabular}

${ }^{\mathrm{a}}$ Component 1 is misinformation and is not included, component 2 is the conspiracy theory that $5 \mathrm{G}$ technology contributes to the spreading of COVID-19, and component 3 is the conspiracy theory that ingesting or injecting bleach can cure COVID-19 infection or kill the virus.

\section{Public Health Safety Measures}

This section investigates the impacts of what people learned through web searches on behaviors toward public health safety measures against COVID-19. Based on the elbow rule, the PCA identified two public health measure components, which we labeled as PubHealthMes1 and PubHealthMes2. The two components accounted for the variability in the search index of keywords used to learn about the public health measures against the spread of COVID-19 (Figure 7). The first and second components explained more than $75.4 \%$ and $18.7 \%$ of the variability, respectively; that is, the first two components explained about $94 \%$ of the variability (Table 6).

Figure 7. Scree plot of public health measures against COVID-19; two components extracted $93.99 \%$ of the variability in the search index.

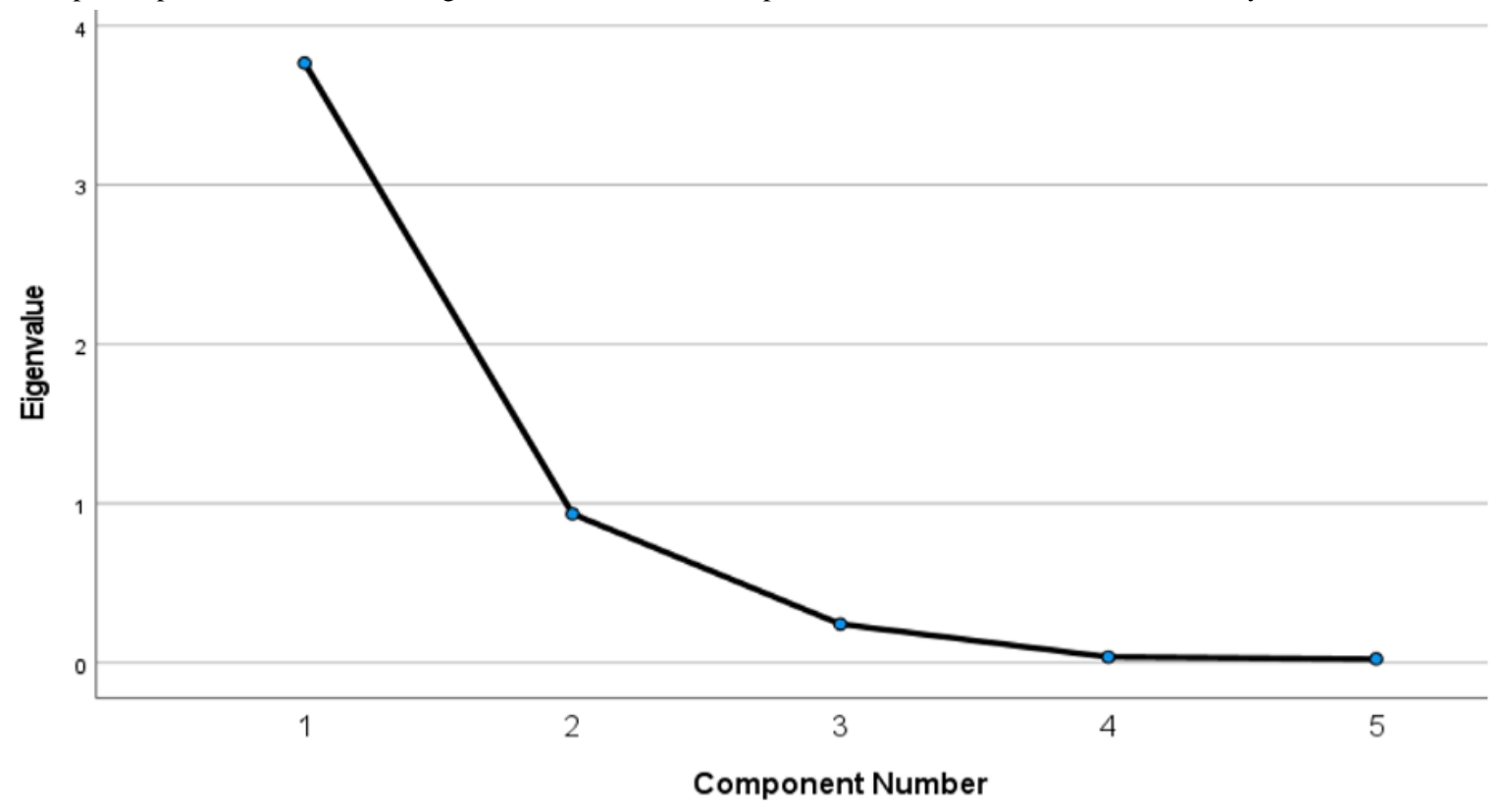

Table 6. Total explained variance for terms that explained the public health measures against COVID-19.

\begin{tabular}{llllll}
\hline Measure & PC $^{\mathrm{a}} 1$ & PC 2 & PC 3 & PC 4 & PC 5 \\
\hline Total initial eigenvalue & 3.768 & 0.933 & 0.24 & 0.035 & 0.023 \\
Variance, $\%$ & 75.359 & 18.665 & 4.799 & 0.71 & 0.466 \\
Cumulative variance, $\%$ & 75.359 & 94.025 & 98.824 & 99.534 & 100 \\
\hline
\end{tabular}

${ }^{\mathrm{a}} \mathrm{PC}$ : principal component.

The first component, PubHealthMes1, includes the keywords "social distancing," "wash hands," "isolation," and "quarantine." In the second component, PubHealthMes2, the keyword "wear mask" explained $84.7 \%$ of the variability (Table 7):
- PubHealthMes $1=0.953$ "social distancing" + 0.847 "wash hands" + 0.953 "isolation" + 0.99 "quarantine"

- PubHealthMes2 = 0.847 "wear mask." 
Table 7. Component matrix and weight loading for terms that explained the public health measures.

\begin{tabular}{llllll}
\hline Component $^{\mathrm{a}}$ & \multicolumn{2}{l}{ Weight loading for each keyword } & & \\
& Quarantine & Social distancing & Isolation & Wash hands & Wear mask \\
\hline 1 & 0.99 & 0.953 & 0.953 & 0.847 & 0.503 \\
2 & -0.028 & 0.143 & -0.223 & -0.38 & 0.847 \\
\hline
\end{tabular}

${ }^{\text {a Component }} 1$ is public health measures represented by the keywords "social distancing," "wash hands," "isolation," and "quarantine," and component 2 is the public health measure represented the keyword "wear mask."

\section{Analysis of the Relationships Among the Principal Components}

This section presents further analysis that tested the hypothesis raised in the earlier section using built predictive models. The variables identified the linear combination of search keywords significantly correlated (loading >0.6) to the principal components discussed in the Results subsections above. Also, Tables 2 to 7 present the underlying latent variables of the 25 search terms used to learn about COVID-19, the misinformation and conspiracy theories, and the public health measures. As stated, Figure 8 shows the underlying variables.

Figure 8. Daily search index of the principal components. ConspTheory 1: conspiracy theory 1; ConspTheory2: conspiracy theory 2; pastCoVepidemics: keywords that address previous epidemics; presCoVpandemic: keywords that explain the ongoing pandemic; PubHealthMes1: public health measures 1; PubHealthMes2: public health measures 2.

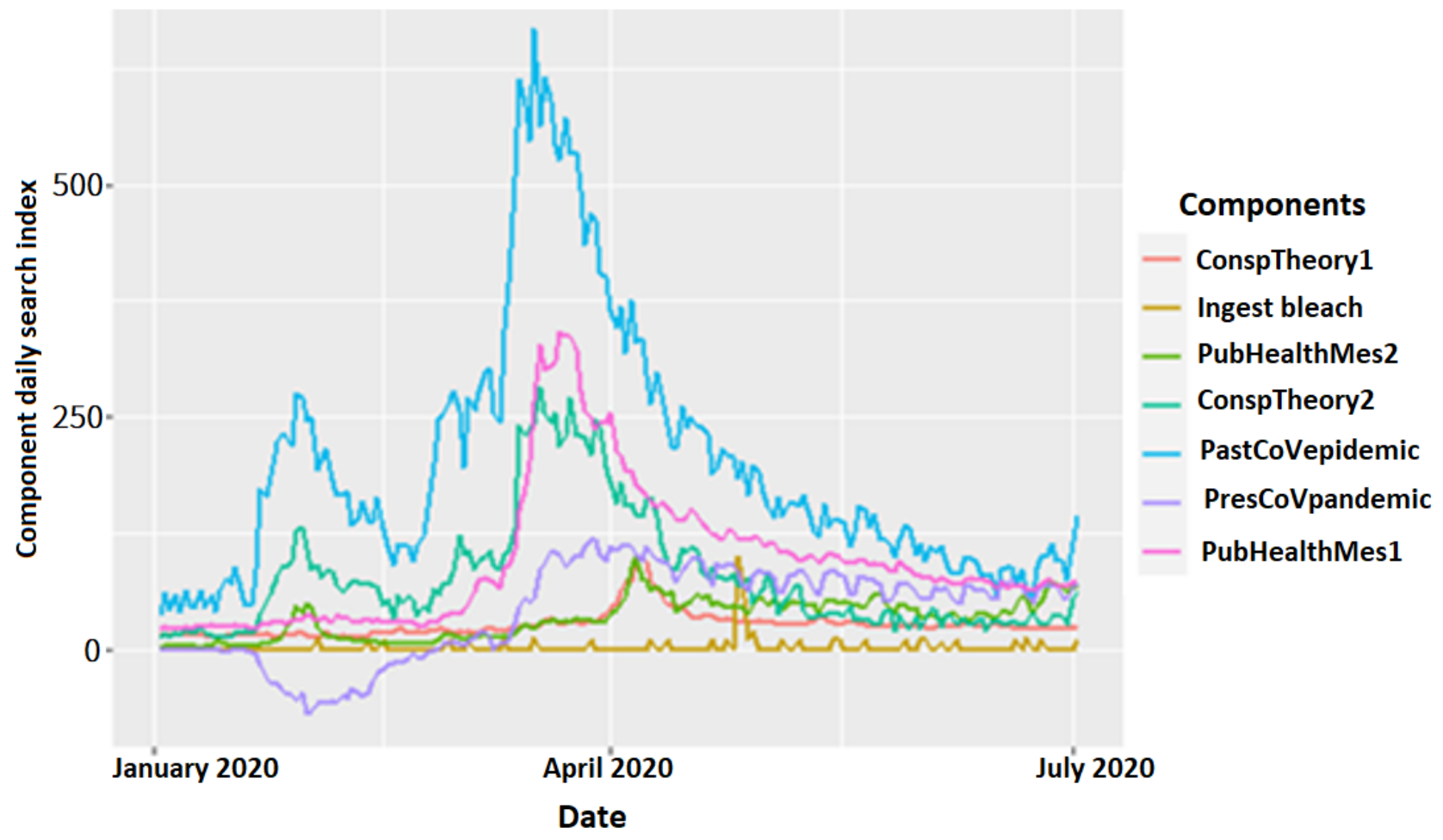

Here, we examine how the underlying variables and the search terms impacted learning and behavior toward the public health measures: learning about COVID-19 (pastCoVepidemics and presCoVpandemic), misinformation and unproven or misleading assertions (misinformation), conspiracy theories (ConspTheory1 and ConspTheory2), and public health safety measures (PubHealthMes1 and PubHealthMes2).

The results show three essential highlights from the daily search index. First, the most popular search terms used at the initial outbreak of the pandemic in early January 2020 were terms representing misinformation and past epidemics. The search keywords that represented conspiracy theories were not used until May 2020. Also, the use of learning terms that directly explained COVID-19 (ie, presCoVpandemic) corresponded with the WHO's naming and renaming of the coronavirus and the disease (ie, "2019-nCoV," "SARS-CoV-2," and "COVID-19") in January, February, and March 2020.

\section{Information Learned Versus Behavior Toward Public Health Measures}

We employed correlation analysis among the variables, scatterplots, and their histograms to examine the relationship between what people learned and their attitudes toward public health measures (Figure 9). 
Figure 9. Panel pair plots of linear correlations between misinformation and conspiracy theory keywords. pastCoVepidemics: keywords that address previous epidemics; presCoVpandemic: keywords that explain the ongoing pandemic; PubHealthMes1: public health measure 1; PubHealthMes2: public health measure 2 .

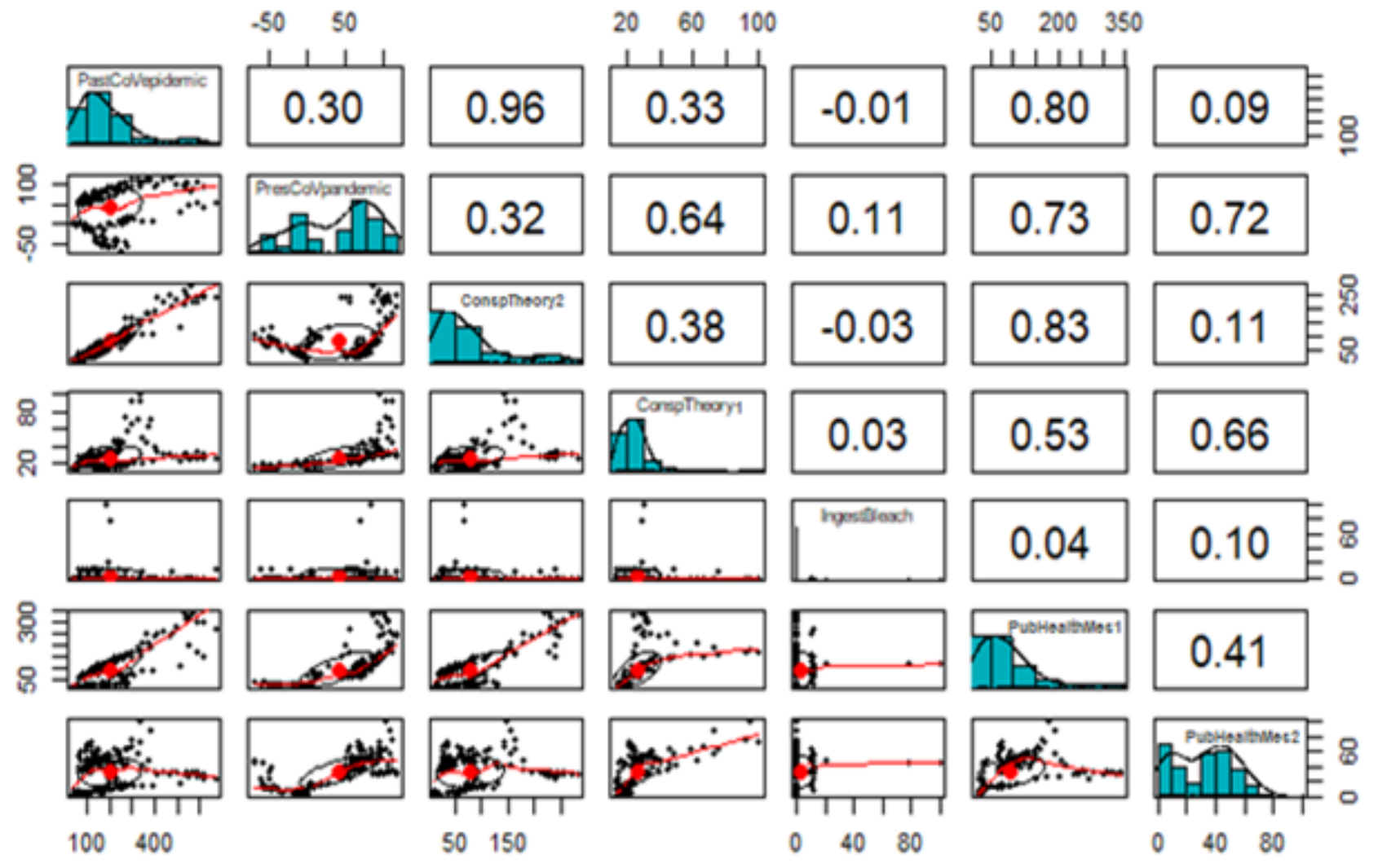

PubHealthMes1 has a robust positive relationship with pastCoVepidemics $(r=0.80)$ and a moderate positive relationship with presCoVpandemic $(r=0.73)$, which implies the effectiveness of learning keywords associated with past coronavirus epidemics (eg, "SARS," "SARS-CoV," "MERS," "MERS-CoV," and more) and the ongoing pandemic (eg, "2019-nCoV," "SARS-CoV-2," and "COVID-19"). Similarly, PubHealthMes2 (ie, wearing a facial mask) has a moderate positive relationship with presCoVpandemic $(r=0.71)$. There is a strong association between actions taken and the information

Given such a strong linear relationship between the search terms and people's behaviors and actions, a multiple linear regression model seems acceptable as a predictive model. But the data failed the assumption of normality, as shown by the quantile-quantile (Q-Q) plots in Figure 10, A and B. A normal Q-Q plot helps to compare two probability distributions, by plotting the residuals against theoretical quantiles. Plots $\mathrm{A}$ and $\mathrm{B}$ in Figure 10 show that most residuals are not lying on the diagonal line; hence, the data are not normally distributed. learned. Figure 9 shows a correlation matrix.

Figure 10. Quantile-quantile (Q-Q) plots of (A) PubHealthMes1 (public health measures 1, represented by the keywords "social distancing," wash hands," "isolation," and "quarantine") and (B) PubHealthMes2 (public health measures 2, represented the keyword "wear mask").
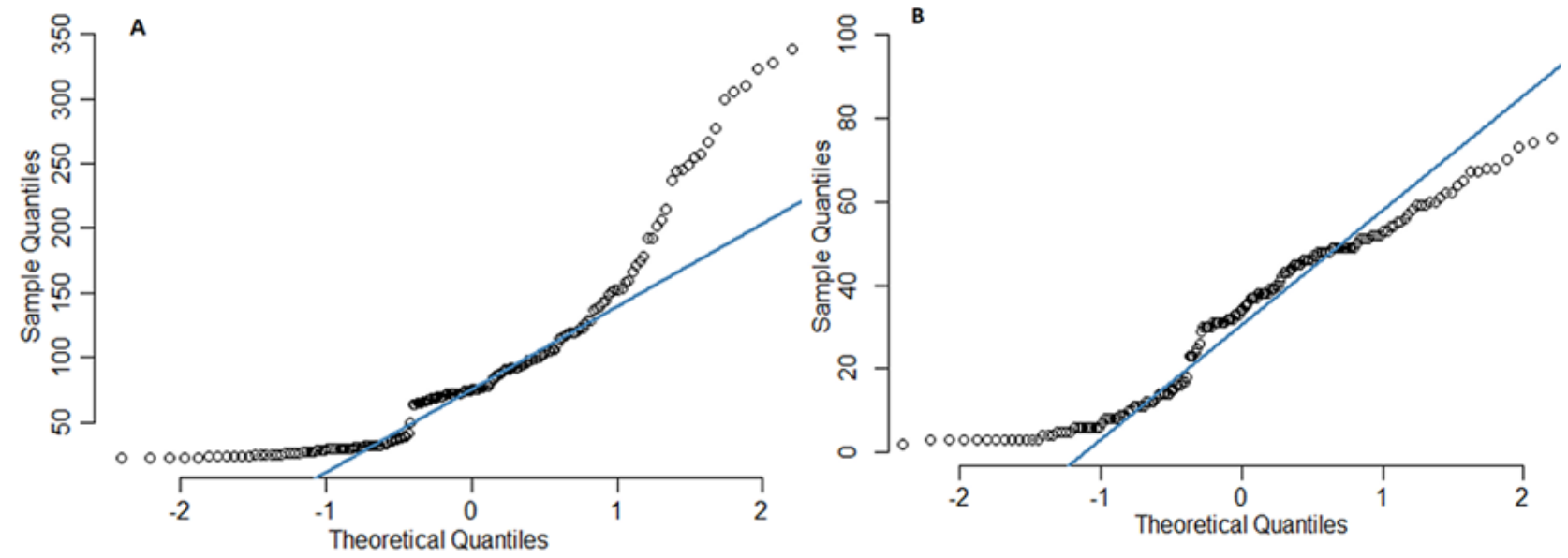
From Figure 9, we can observe that the PubHealthMes1 histogram suggests a right-skewed distribution, while the PubHealthMes2 histogram suggests a bimodal distribution. To describe and explain the relationship between the public health measures and the terms that contributed to learning about COVID-19, misinformation, and conspiracy theories, we used the log-linear predictive model, since the data are based on a number of occurrences or frequency and not normally distributed. Also, the log-linear model does not need to satisfy any assumptions, which we represent as follows:

$$
\log \left(Y_{i}\right)=\beta_{0}+\sum_{i=1}^{m} \beta_{i} x_{i} i=1, \ldots, m
$$

where $x_{i}$ is the covariate and $\beta_{i}$ is the parameter to be estimated.

The data obtained through the PCA have been fitted to a log-linear regression model using RStudio tools from $\mathrm{R}$ (version 4.0.5; The $\mathrm{R}$ Foundation). The regression model obtained becomes the following:

$$
\begin{aligned}
& \log (\text { PubHealthMes1) }=3.33+0.0024 \\
& \text { pastCoVepidemics }+0.011 \text { presCoVpandemic }
\end{aligned}
$$

The $R^{2}$ of the model is 0.93 and the $\mathrm{P}$ value is <.001. All the coefficients in this model are significant at an $\alpha$ level of 0 . From the model, we see that there is a 1.10 percentage $\left(100 \times\left[\exp ^{0.011}\right.\right.$ $-1] \%$ ) increase in the public health measure for every $1 \%$ increase in presCoVpandemic (ie, "2019-nCoV," "SARS-CoV-2," and "COVID-19"). This may be explained by links contained in recent COVID-19 pandemic articles on public health measures. For every $1 \%$ increase in past epidemic searches, there is a $0.25 \%$ increase in the searches of public health measures. Similarly, the regression model for PubHealthMes2 obtained becomes the following:

\section{$\log ($ PubHealthMes 2$)=0.01 \times$ presCoVpandemic +} 2.35

The $R^{2}$ of the new model is 0.50 and the $\mathrm{P}$ value is $<.001$. The two models show that both PubHealthMes1 and PubHealthMes2 are significantly predictive using the presCoVpandemic keywords. It shows that learning about the present pandemic creates an incentive for people to learn about public health measures, which we can approximate to a desired intention to comply with the measures.

\section{Misinformation, Conspiracy Theories, and Public Health Measures}

This section examines the relationship between conspiracy theories, misinformation, and public health measures using correlation and predictive analyses. As discussed earlier, we recategorized the search terms representing misinformation and conspiracy theories into two principal components. Hypothesis $3 \mathrm{~A}$, as defined in the Research Hypotheses section, focuses on misinformation and public health guidelines. At the same time, Hypothesis $3 \mathrm{~B}$ addresses the impact of conspiracy theories on people's behavior toward the same safety measures.

Using correlation analysis to evaluate the association between conspiracy theories and public health measures, we observed a moderate positive linear association between ConspTheory2 and PubHealthMes2 $(r=0.66)$ and a moderate linear relationship between ConspTheory1 and PubHealthMes1 $(r=0.53)$. The log-linear analysis showed that conspiracy theories are not significant predictors of PubHealthMes1 $(P=.62)$ but are for PubHealthMes2 $(P=.008)$. Thus, the null hypothesis that there is no association between conspiracy theories (ie, ConspTheory1) and people's responses to public health (ie, wearing facial masks to limit the spread of COVID-19) is rejected. We can conclude that conspiracy theories are predictive of people's behaviors in wearing facial masks.

We also analyzed the relationship between misinformation and behavior toward public health measures. Although the correlation and the predictive analyses showed a moderate positive linear relationship between misinformation and PubHealthMes1 $(r=0.83)$, it is not predictive. The relationship between the two variables is just mathematical but not causal. Despite a negligible negative linear relationship between misinformation and wearing a facial mask $(r=0.11)$, the log-linear model shows that misinformation is not a significant predictor for both PubHealthMes $1(P=.27)$ and PubHealthMes2 $(P=.13)$. Notwithstanding the strong linear relationship between web searches to learn about misinformation and public health measures, there is no sufficient evidence to reject the null hypothesis. We can conclude that there is no association between learning about COVID-19 misinformation and people's response to public health guidelines.

\section{Discussion}

\section{Principal Findings}

We found that people used search keywords related to past coronavirus epidemics (pastCoVepidemics) and the ongoing pandemic (presCoVpandemic) to learn about SARS-CoV-2 and COVID-19. However, the attention accorded to the pandemic led to less focus on terms relating to perennial illnesses (eg, "common cold," "flu," and more). These results corroborate studies reporting the unintended positive consequences of COVID-19 leading to declines in cases of influenza, flu, and similar infections (eg, Soo et al [46]). Other learning terms employed were keywords that addressed the pandemic directly. The average search indexes for those keywords were 19.01 for "nCoV" and "2019-nCoV," 39.75 for "SARS-CoV-2," and 32.40 for "COVID-19."

Studies examining learning by web searching emphasized the significance of the search terms or phrases on what the users intended to learn. A trending word on the web indicates what information people are interested in learning $[11,61,66]$. This study identified the 25 most-used keywords to learn about SARS-CoV-2 and COVID-19 through web searches.

Regarding the impacts of what people learned on their behavior toward public health measures, the PCA identified three latent variables, classified as misinformation, ConspTheory1, and ConspTheory2. Only ConspTheory1 (“@5G”) directly and significantly influenced people's behavior toward public health measures (ie, PubHealthMes2 ["wear mask"]). The conspiracy that 5G technology enhances the easy spread of COVID-19 [14] 
highlights danger, which can cause people to take precautions. A different study [15] identified erroneous beliefs in the 5G conspiracy theory as leading to the hoarding of essential goods during the initial period of the SAR-CoV-2 outbreak. Although there was a high correlation between misinformation (Tables 4 and 5) and behavior toward public health measures, this was not statistically significant based on the web search index. Also, as the pandemic lingers, thereby causing severe health and social crises, strains in family relations, and economic and business losses, many people are becoming increasingly aware of COVID-19 dangers [21,57,67-69]. Through direct impacts or by experience, this can cause changes in people's behavior irrespective of whether they believed the misinformation or not.

\section{Strengths and Limitations}

Internet platforms continue to play a significant role in health communication during the ongoing COVID-19 pandemic. Some studies attribute the increase in misinformation and conspiracy theories about COVID-19 in different countries to web searches, social media use, and online news media platforms that are used to learn about SARS-CoV-2 and COVID-19 [10,11,29]. However, most studies were anecdotal with no empirical evidence. Using Google Trends data, this study provides the first empirical evidence to this discourse. In the era of big data, the analysis of Google queries can be envisioned as a valuable tool for researchers to explore and predict human behavior, especially as studies suggest that online data can correlate with actual health data [70,71].

Infodemiology studies have their limitations too. While Google search keywords are short and easy to classify automatically, interpreting the terms semantically can be challenging. It is not clear why people are searching for these keywords. Furthermore, when using Google Trends, the sample is unknown and may not be representative, and individuals using the internet are not representative of the entire population. They are more likely to be younger, more educated, earn higher incomes, and reside in urban areas [18]. Individuals who are more likely to be severely affected by COVID-19 are not usually represented by this population [72,73]. Despite the identified limitations, previous studies suggest that web-based data provide valuable and valid results in exploring and predicting behavior and highly correlate with actual data [70,71]. Further, there are reports of rapid penetration of internet access and usage in different parts of the world, except for in regions with low internet penetration or countries with low scores in freedom of speech $[22,74,75]$.

\section{Conclusions}

The results of this empirical infodemiology study showed that a good portion of the global population learned about the outbreak of SARS-CoV-2 and COVID-19 through web searches, particularly in the early period of the pandemic. The period covers the initial days, weeks, and months from the emergence of the novel coronavirus in January 2020 up to June 30, 2020, when the public became more aware of the pandemic, especially after the first wave [1].

The PCA showed that people used the web to learn about the ongoing COVID-19 pandemic in two ways, namely, using pastCoVepidemics keywords and using presCoVpandemic keywords. The use of pastCoVepidemics keywords in web searches nosedived as the WHO formally named the novel coronavirus and the disease (ie, "nCoV," "2019-nCoV," "SARS-CoV-2," and "COVID-19") and, therefore, as these terms became available. The trends analysis showed that web searches used to learn about COVID-19 followed a similar trend as learning about public health measures, implying that the more that people focused their attention on learning about SARS-CoV-2 and COVID-19, the more they also learned about public health measures, and vice versa. Interestingly, learning about the conspiracy theory (ConspTheory1) that 5G technology contributes to the fast global spread of COVID-19 is a predictor of people's behavior toward public health measures (PubHealthMes2). This erroneous belief makes people take precautionary measures, such as wearing a facial mask, although borne out of fear $[14,15]$. The same studies using the survey method also identified the same 5G-related conspiracy theory as making people respond out of fear to take precautions. This factor contributed to stockpiling of goods in the early days of the pandemic [15]. This study is the first to examine what people learned through web searches and how these influence people's social behavior toward public health safety guidelines.

\section{Conflicts of Interest}

None declared.

\section{Multimedia Appendix 1}

Summary statistics of the normalized daily global Google Trends scores for different keywords used in this study. Data correspond to the time window between January 1, 2020, and June 30, 2020 ( $\mathrm{N}=182$ data points).

[DOCX File, 18 KB-Multimedia Appendix 1]

\section{References}

1. Lu H, Stratton CW, Tang YW. Outbreak of pneumonia of unknown etiology in Wuhan, China: The mystery and the miracle. J Med Virol 2020 Apr;92(4):401-402 [FREE Full text] [doi: 10.1002/jmv.25678] [Medline: $\underline{31950516}$ ]

2. Huang C, Wang Y, Li X, Ren L, Zhao J, Hu Y, et al. Clinical features of patients infected with 2019 novel coronavirus in Wuhan, China. Lancet 2020 Feb 15;395(10223):497-506 [FREE Full text] [doi: 10.1016/S0140-6736(20)30183-5] [Medline: 31986264] 
3. Wu JT, Leung K, Leung GM. Nowcasting and forecasting the potential domestic and international spread of the 2019-nCoV outbreak originating in Wuhan, China: A modelling study. Lancet 2020 Feb 29;395(10225):689-697 [FREE Full text] [doi: 10.1016/S0140-6736(20)30260-9] [Medline: 32014114]

4. Chan JF, Kok K, Zhu Z, Chu H, To KK, Yuan S, et al. Genomic characterization of the 2019 novel human-pathogenic coronavirus isolated from a patient with atypical pneumonia after visiting Wuhan. Emerg Microbes Infect 2020 Jan 28;9(1):221-236 [FREE Full text] [doi: 10.1080/22221751.2020.1719902] [Medline: 31987001]

5. Woo J, Lee EY, Lee M, Kim T, Cho Y. An in vivo cell-based assay for investigating the specific interaction between the SARS-CoV N-protein and its viral RNA packaging sequence. Biochem Biophys Res Commun 2019 Dec 10;520(3):499-506 [FREE Full text] [doi: 10.1016/j.bbrc.2019.09.115] [Medline: $\underline{\text { 31594639] }}$

6. WHO statement regarding cluster of pneumonia cases in Wuhan, China. World Health Organization. 2020 Jan 09. URL: https://www.who.int/china/news/detail/09-01-2020-who-statement-regarding-cluster-of-pneumonia-cases-in-wuhan-china [accessed 2020-12-01]

7. Labrague LJ, Yboa BC, McEnroe-Petitte DM, Lobrino LR, Brennan MGB. Disaster preparedness in Philippine nurses. J Nurs Scholarsh 2016 Jan;48(1):98-105. [doi: 10.1111/jnu.12186] [Medline: 26650188]

8. Atzrodt CL, Maknojia I, McCarthy RDP, Oldfield TM, Po J, Ta KTL, et al. A guide to COVID-19: A global pandemic caused by the novel coronavirus SARS-CoV-2. FEBS J 2020 Sep;287(17):3633-3650 [FREE Full text] [doi:

10.1111/febs.15375] [Medline: 32446285]

9. Events as they happen: Rolling updates on coronavirus disease (COVID-19). World Health Organization. 2020. URL: https://www.who.int/emergencies/diseases/novel-coronavirus-2019/events-as-they-happen [accessed 2020-10-31]

10. Dadaczynski K, Okan O, Messer M, Leung AYM, Rosário R, Darlington E, et al. Digital health literacy and web-based information-seeking behaviors of university students in Germany during the COVID-19 pandemic: Cross-sectional survey study. J Med Internet Res 2021 Jan 15;23(1):e24097 [FREE Full text] [doi: 10.2196/24097] [Medline: 33395396]

11. Rovetta A, Bhagavathula AS. COVID-19-related web search behaviors and infodemic attitudes in Italy: Infodemiological study. JMIR Public Health Surveill 2020 May 05;6(2):e19374 [FREE Full text] [doi: 10.2196/19374] [Medline: 32338613]

12. Sulyok M, Ferenci T, Walker M. Google Trends data and COVID-19 in Europe: Correlations and model enhancement are European wide. Transbound Emerg Dis 2021 Jul;68(4):2610-2615. [doi: 10.1111/tbed.13887] [Medline: 33085851]

13. Akpan IJ, Aguolu OG, Akpan A. An empirical analysis of what people learned about COVID-19 through a web search and the impacts on misinformation and attitude towards public health safety guidelines. medRxiv. Preprint posted online on February 26, 2021. [FREE Full text] [doi: 10.1101/2021.02.23.21252323]

14. Miller JM. Do COVID-19 conspiracy theory beliefs form a monological belief system? Can J Polit Sci 2020 May 21;53(2):319-326. [doi: 10.1017/S0008423920000517]

15. Miller JM. Psychological, political, and situational factors combine to boost COVID-19 conspiracy theory beliefs. Can J Polit Sci 2020 Jun 11;53(2):327-334. [doi: 10.1017/s000842392000058x]

16. Allington D, Duffy B, Wessely S, Dhavan N, Rubin J. Health-protective behaviour, social media usage and conspiracy belief during the COVID-19 public health emergency. Psychol Med 2020 Jun 09;51(10):1763-1769. [doi: $10.1017 / \mathrm{s} 003329172000224 \mathrm{x}]$

17. Hornik R, Kikut A, Jesch E, Woko C, Siegel L, Kim K. Association of COVID-19 misinformation with face mask wearing and social distancing in a nationally representative US sample. Health Commun 2021 Jan;36(1):6-14. [doi: 10.1080/10410236.2020.1847437] [Medline: 33225745]

18. Eysenbach G. Infodemiology and infoveillance: Framework for an emerging set of public health informatics methods to analyze search, communication and publication behavior on the internet. J Med Internet Res 2009 Mar 27;11(1):e11 [FREE Full text] [doi: 10.2196/jmir.1157] [Medline: 19329408]

19. Eysenbach G. Infodemiology and infoveillance tracking online health information and cyberbehavior for public health. Am J Prev Med 2011 May;40(5 Suppl 2):S154-S158. [doi: 10.1016/j.amepre.2011.02.006] [Medline: 21521589]

20. Mavragani A. Infodemiology and infoveillance: Scoping review. J Med Internet Res 2020 Apr 28;22(4):e16206 [FREE Full text] [doi: 10.2196/16206] [Medline: 32310818]

21. Akpan IJ, Soopramanien D, Kwak DH. Cutting-edge technologies for small business and innovation in the era of COVID-19 global health pandemic. J Small Bus Entrepreneurship 2020 Aug 21:1-11. [doi: 10.1080/08276331.2020.1799294]

22. Akpan IJ, Ibidunni AS. Digitization and technological transformation of small business for sustainable development in the less developed and emerging economies: A research note and call for papers. J Small Bus Entrepreneurship 2021 May 18:1-7. [doi: 10.1080/08276331.2021.1924505]

23. Neely S, Eldredge C, Sanders R. Health information seeking behaviors on social media during the COVID-19 pandemic among American social networking site users: Survey study. J Med Internet Res 2021 Jun 11;23(6):e29802 [FREE Full text] [doi: 10.2196/29802] [Medline: $\underline{34043526}$ ]

24. Bautista JR, Zhang Y, Gwizdka J. Healthcare professionals' acts of correcting health misinformation on social media. Int J Med Inform 2021 Apr;148:104375. [doi: 10.1016/j.ijmedinf.2021.104375] [Medline: 33461008]

25. Ahmed W, Vidal-Alaball J, Downing J, López Seguí F. COVID-19 and the 5G conspiracy theory: Social network analysis of Twitter data. J Med Internet Res 2020 May 06;22(5):e19458 [FREE Full text] [doi: 10.2196/19458] [Medline: 32352383] 
26. Garrett L. COVID-19: The medium is the message. Lancet 2020 Mar 21;395(10228):942-943 [FREE Full text] [doi: 10.1016/S0140-6736(20)30600-0] [Medline: 32171075]

27. Fleming N. Coronavirus misinformation, and how scientists can help to fight it. Nature 2020 Jul;583(7814):155-156. [doi: 10.1038/d41586-020-01834-3] [Medline: 32601491]

28. Lee JJ, Kang K, Wang MP, Zhao SZ, Wong JYH, O'Connor S, et al. Associations between COVID-19 misinformation exposure and belief with COVID-19 knowledge and preventive behaviors: Cross-sectional online study. J Med Internet Res 2020 Nov 13;22(11):e22205 [FREE Full text] [doi: 10.2196/22205] [Medline: 33048825]

29. Kim HK, Ahn J, Atkinson L, Kahlor LA. Effects of COVID-19 misinformation on information seeking, avoidance, and processing: A multicountry comparative study. Sci Commun 2020 Sep 13;42(5):586-615. [doi: 10.1177/1075547020959670]

30. Nuti SV, Wayda B, Ranasinghe I, Wang S, Dreyer RP, Chen SI, et al. The use of Google Trends in health care research: A systematic review. PLoS One 2014;9(10):e109583 [FREE Full text] [doi: 10.1371/journal.pone.0109583] [Medline: 25337815]

31. Chung M, Oden RP, Joyner BL, Sims A, Moon RY. Safe infant sleep recommendations on the internet: Let's Google it. J Pediatr 2012 Dec;161(6):1080-1084 [FREE Full text] [doi: 10.1016/j.jpeds.2012.06.004] [Medline: 22863258]

32. Goldie JGS. Connectivism: A knowledge learning theory for the digital age? Med Teach 2016 Oct;38(10):1064-1069. [doi: 10.3109/0142159X.2016.1173661] [Medline: 27128290]

33. Dunaway MK. Connectivism: Learning theory and pedagogical practice for networked information landscapes. Ref Serv Rev 2011 Nov 15;39(4):675-685. [doi: 10.1108/00907321111186686]

34. Mian A, Khan S. Coronavirus: The spread of misinformation. BMC Med 2020 Mar 18;18(1):89 [FREE Full text] [doi: 10.1186/s12916-020-01556-3] [Medline: 32188445]

35. Lima-Pereira P, Bermúdez-Tamayo C, Jasienska G. Use of the internet as a source of health information amongst participants of antenatal classes. J Clin Nurs 2012 Feb;21(3-4):322-330. [doi: 10.1111/j.1365-2702.2011.03910.x] [Medline: 22093043]

36. Cervellin G, Comelli I, Lippi G. Is Google Trends a reliable tool for digital epidemiology? Insights from different clinical settings. J Epidemiol Glob Health 2017 Sep;7(3):185-189 [FREE Full text] [doi: 10.1016/j.jegh.2017.06.001] [Medline: 28756828]

37. Schunk DH. Self-regulated learning: The educational legacy of Paul R Pintrich. Educ Psychol 2005 Jun;40(2):85-94. [doi: $10.1207 / \mathrm{s} 15326985 \mathrm{ep} 4002 \quad 3]$

38. Akpan IJ. Formative assessment as a technique for improving student engagement and learning effectiveness in self-regulated e-learning environment. In: Proceedings of the IEICE Information and Communication Technology Forum. 2014 Aug 10 Presented at: IEICE Information and Communication Technology Forum; May 28-30, 2014; Poznań, Poland p. 34 URL: https://www.ieice.org/publications/proceedings/bin/pdf_link.php?fname=COMM1-2. pdf\&iconf=ICTF\&year=2014\&vol=19\&number=COMM1-2\&lang=E [doi: 10.34385/proc.19.COMM1-2]

39. Donthu N, Gustafsson A. Effects of COVID-19 on business and research. J Bus Res 2020 Sep;117:284-289 [FREE Full text] [doi: 10.1016/j.jbusres.2020.06.008] [Medline: 32536736]

40. Tuite AR, Zhu L, Fisman DN, Salomon JA. Alternative dose allocation strategies to increase benefits from constrained COVID-19 vaccine supply. Ann Intern Med 2021 Apr;174(4):570-572 [FREE Full text] [doi: 10.7326/M20-8137] [Medline: 33395334]

41. Shrivastava S, Shrivastava P. Minimizing the risk of international spread of coronavirus disease 2019 (COVID-19) outbreak by targeting travelers. J Acute Dis 2020;9(2):47. [doi: 10.4103/2221-6189.278654]

42. van Doremalen N, Bushmaker T, Morris DH, Holbrook MG, Gamble A, Williamson BN, et al. Aerosol and surface stability of SARS-CoV-2 as compared with SARS-CoV-1. N Engl J Med 2020 Apr 16;382(16):1564-1567. [doi: 10.1056/nejmc2004973]

43. Ai T, Yang Z, Hou H, Zhan C, Chen C, Lv W, et al. Correlation of chest CT and RT-PCR testing for coronavirus disease 2019 (COVID-19) in China: A report of 1014 cases. Radiology 2020 Aug;296(2):E32-E40 [FREE Full text] [doi: 10.1148/radiol.2020200642] [Medline: $\underline{\text { 32101510] }}$

44. Interim clinical guidance for management of patients with confirmed coronavirus disease (COVID-19). Centers for Disease Control Prevention. 2020. URL: https://www.cdc.gov/coronavirus/2019-ncov/hcp/clinical-guidance-management-patients. html [accessed 2020-12-02]

45. COVID-19 Treatment Guidelines Panel. Coronavirus Disease 2019 (COVID-19) Treatment Guidelines. Bethesda, MD: National Institutes of Health; 2020. URL: https://files.covid19treatmentguidelines.nih.gov/guidelines/ covid19treatmentguidelines.pdf [accessed 2021-08-25]

46. Soo RJJ, Chiew CJ, Ma S, Pung R, Lee V. Decreased influenza incidence under COVID-19 control measures, Singapore. Emerg Infect Dis 2020 Aug;26(8):1933-1935 [FREE Full text] [doi: 10.3201/eid2608.201229] [Medline: 32339092]

47. Mavragani A, Ochoa G. Google Trends in infodemiology and infoveillance: Methodology framework. JMIR Public Health Surveill 2019 May 29;5(2):e13439 [FREE Full text] [doi: 10.2196/13439] [Medline: 31144671]

48. Akpan IJ, Akpan AA. Multiple criteria analysis of the popularity and growth of research and practice of visual analytics, and a forecast of the future trajectory. Int Trans Oper Res 2021 Feb 26;28(5):2275-2298. [doi: 10.1111/itor.12952]

49. Brodeur A, Clark AE, Fleche S, Powdthavee N. COVID-19, lockdowns and well-being: Evidence from Google Trends. J Public Econ 2021 Jan;193:104346 [FREE Full text] [doi: 10.1016/j.jpubeco.2020.104346] [Medline: 33281237] 
50. Masters-Waage TC, Jha N, Reb J. COVID-19, coronavirus, Wuhan virus, or China virus? Understanding how to "do no harm" when naming an infectious disease. Front Psychol 2020;11:561270 [FREE Full text] [doi: 10.3389/fpsyg.2020.561270] [Medline: $\underline{33362626}$ ]

51. Jo S, Kim H, Kim S, Shin DH, Kim M. Characteristics of flavonoids as potent MERS-CoV 3C-like protease inhibitors. Chem Biol Drug Des 2019 Dec;94(6):2023-2030 [FREE Full text] [doi: 10.1111/cbdd.13604] [Medline: 31436895]

52. Xie M, Chen Q. Insight into 2019 novel coronavirus - An updated interim review and lessons from SARS-CoV and MERS-CoV. Int J Infect Dis 2020 May;94:119-124 [FREE Full text] [doi: 10.1016/j.ijid.2020.03.071] [Medline: 32247050]

53. Mahase E. Coronavirus COVID-19 has killed more people than SARS and MERS combined, despite lower case fatality rate. BMJ 2020 Feb 18;368:m641. [doi: 10.1136/bmj.m641] [Medline: $\underline{\text { 32071063] }}$

54. Naming the coronavirus disease (COVID-19) and the virus that causes it. World Health Organization. 2020. URL: https:/ /www.who.int/emergencies/diseases/novel-coronavirus-2019/technical-guidance/ naming-the-coronavirus-disease-(covid-2019)-and-the-virus-that-causes-it [accessed 2020-12-01]

55. Coronavirus disease (COVID-19) weekly epidemiological update and weekly operational update. World Health Organization. 2020. URL: https://www.who.int/emergencies/diseases/novel-coronavirus-2019 [accessed 2020-12-01]

56. Chary MA, Overbeek DL, Papadimoulis A, Sheroff A, Burns MM. Geospatial correlation between COVID-19 health misinformation and poisoning with household cleaners in the Greater Boston Area. Clin Toxicol (Phila) 2021 Apr;59(4):320-325. [doi: 10.1080/15563650.2020.1811297] [Medline: 32901533]

57. Matias T, Dominski FH, Marks DF. Human needs in COVID-19 isolation. J Health Psychol 2020 Jun;25(7):871-882. [doi: 10.1177/1359105320925149] [Medline: 32375564]

58. Leung CC, Lam TH, Cheng KK. Mass masking in the COVID-19 epidemic: People need guidance. Lancet 2020 Mar 21;395(10228):945 [FREE Full text] [doi: 10.1016/S0140-6736(20)30520-1] [Medline: 32142626]

59. De Giorgio A. COVID-19 is not just a flu. Learn from Italy and act now. Travel Med Infect Dis 2020;35:101655 [FREE Full text] [doi: 10.1016/j.tmaid.2020.101655] [Medline: 32272199]

60. Akpan IJ, Aguolu OG, Ezeume IC. Overcoming the challenge of communicating the concept and science of SARS-CoV-2 and COVID-19 to non-experts. Challenge 2021 May 04;64(2):117-131. [doi: 10.1080/05775132.2021.1912984]

61. Roscoe RD, Grebitus C, O'Brian J, Johnson AC, Kula I. Online information search and decision making: Effects of web search stance. Comput Human Behav 2016 Mar;56:103-118. [doi: 10.1016/j.chb.2015.11.028]

62. Sanchez-Caballero S, Selles MA, Peydro MA, Perez-Bernabeu E. An efficient COVID-19 prediction model validated with the cases of China, Italy and Spain: Total or partial lockdowns? J Clin Med 2020 May 20;9(5):1547 [FREE Full text] [doi: 10.3390/jcm9051547] [Medline: 32443871]

63. Akpan IJ, Shanker M, Razavi R. Improving the success of simulation projects using 3D visualization and virtual reality. J Oper Res Soc 2019 Sep 12;71(12):1900-1926. [doi: 10.1080/01605682.2019.1641649]

64. Pickles K, Cvejic E, Nickel B, Copp T, Bonner C, Leask J, et al. COVID-19 misinformation trends in Australia: Prospective longitudinal national survey. J Med Internet Res 2021 Jan 07;23(1):e23805 [FREE Full text] [doi: 10.2196/23805] [Medline: $\underline{33302250]}$

65. Krehbiel TC. SAS. In: Ross PW, editor. The Handbook of Software for Engineers and Scientists. Boca Raton, FL: CRC Press; May 04, 2018:1047-1066.

66. Hölscher C, Strube G. Web search behavior of internet experts and newbies. Comput Netw 2000 Jun;33(1-6):337-346. [doi: 10.1016/s1389-1286(00)00031-1]

67. Akpan IJ, Udoh EAP, Adebisi B. Small business awareness and adoption of state-of-the-art technologies in emerging and developing markets, and lessons from the COVID-19 pandemic. J Small Bus Entrepreneurship 2020 Sep 29:1-18. [doi: $10.1080 / 08276331.2020 .1820185]$

68. Lebow JL. The challenges of COVID-19 for divorcing and post-divorce families. Fam Process 2020 Sep;59(3):967-973 [FREE Full text] [doi: 10.1111/famp.12574] [Medline: $\underline{\text { 32594521] }}$

69. Akpan IJ, Ezeume IC. The challenges faced by parents and children from divorce. Challenge 2020 Nov 09;63(6):365-377. [doi: 10.1080/05775132.2020.1842025]

70. Mavragani A, Ochoa G. The internet and the anti-vaccine movement: Tracking the 2017 EU measles outbreak. Big Data Cognit Comput 2018 Jan 16;2(1):2-18. [doi: 10.3390/bdcc2010002]

71. Jun S, Yoo HS, Choi S. Ten years of research change using Google Trends: From the perspective of big data utilizations and applications. Technol Forecast Soc Change 2018 May;130(2018):69-87. [doi: 10.1016/j.techfore.2017.11.009]

72. Ko J, Danielson M, Town M, Derado G, Greenlund K, Kirley P, COVID-NET Surveillance Team. Risk factors for coronavirus disease 2019 (COVID-19)-associated hospitalization: COVID-19-Associated Hospitalization Surveillance Network and Behavioral Risk Factor Surveillance System. Clin Infect Dis 2021 Jun 01;72(11):e695-e703 [FREE Full text] [doi: 10.1093/cid/ciaa1419] [Medline: 32945846]

73. Pijls BG, Jolani S, Atherley A, Derckx RT, Dijkstra JIR, Franssen GHL, et al. Demographic risk factors for COVID-19 infection, severity, ICU admission and death: A meta-analysis of 59 studies. BMJ Open 2021 Jan 11;11(1):e044640 [FREE Full text] [doi: 10.1136/bmjopen-2020-044640] [Medline: 33431495]

74. Akpan IJ, Akpan AA. The impact of internet use on students' learning outcomes in higher education in developing countries. Int J Education Res 2017 Sep;12(1):45-54 [FREE Full text] 
75. Mavragani A, Tsagarakis KP. Predicting referendum results in the big data era. J Big Data 2019 Jan 14;6:1-20 [FREE Full text] [doi: 10.1186/s40537-018-0166-z]

\section{Abbreviations}

2019-nCoV: 2019 novel coronavirus

CDC: Centers for Disease Control and Prevention

ConspTheory1: conspiracy theory 1

ConspTheory2: conspiracy theory 2

MERS: Middle East respiratory syndrome

pastCoVepidemics: keywords that address previous epidemics

PCA: principal component analysis

presCoVpandemic: keywords that explain the ongoing pandemic

PubHealthMes1: public health measures 1

PubHealthMes2: public health measures 2

Q-Q: quantile-quantile

SARS: severe acute respiratory syndrome

WHO: World Health Organization

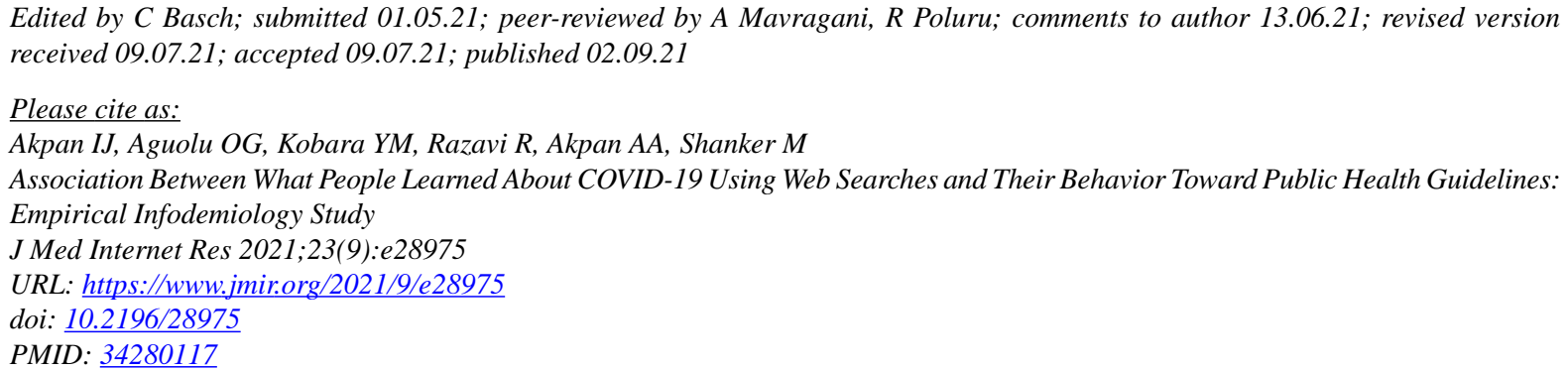

CIkpe Justice Akpan, Obianuju Genevieve Aguolu, Yawo Mamoua Kobara, Rouzbeh Razavi, Asuama A Akpan, Murali Shanker. Originally published in the Journal of Medical Internet Research (https://www.jmir.org), 02.09.2021. This is an open-access article distributed under the terms of the Creative Commons Attribution License (https://creativecommons.org/licenses/by/4.0/), which permits unrestricted use, distribution, and reproduction in any medium, provided the original work, first published in the Journal of Medical Internet Research, is properly cited. The complete bibliographic information, a link to the original publication on https://www.jmir.org/, as well as this copyright and license information must be included. 